\title{
Diversity and functions of intestinal mononuclear phagocytes
}

\author{
T Joeris ${ }^{1,2,4}, \mathrm{~K}$ Müller-Luda ${ }^{2,4}$, WW Agace ${ }^{1,2,5}$ and A McI Mowat ${ }^{3,5}$
}

The intestinal lamina propria (LP) contains a diverse array of mononuclear phagocyte (MNP) subsets, including conventional dendritic cells (cDC), monocytes and tissue-resident macrophages $(\mathrm{m} \phi)$ that collectively play an essential role in mucosal homeostasis, infection and inflammation. In the current review we discuss the function of intestinal cDC and monocyte-derived MNP, highlighting how these subsets play several non-redundant roles in the regulation of intestinal immune responses. While much remains to be learnt, recent findings also underline how the various populations of MNP adapt to deal with the challenges specific to their environment. Understanding these processes should help target individual subsets for 'fine tuning' immunological responses within the intestine, a process that may be of relevance both for the treatment of inflammatory bowel disease (IBD) and for optimized vaccine design.

\section{DEFINING MURINE INTESTINAL MONONUCLEAR PHAGOCYTE SUBSETS}

Conventional dendritic cells $(\mathrm{cDC})$ and macrophages $(\mathrm{m} \phi)$ are found throughout the intestinal LP, but much remains to be understood about the precise function of each cell type. In part, this is because they are difficult to isolate, but to a great extent it reflects the imprecise ways in which they were identified until recently. ${ }^{1-3}$ Thus it is now clear that markers such as CD11c, CD11b and major histocompatability complex II (MHCII) are not sufficient to distinguish between $\mathrm{CDC}$ and $\mathrm{m} \phi$ in many tissues, including the intestine. This is because most mature intestinal $\mathrm{m} \phi$ express as high levels of all these molecules as $\mathrm{CDC}$ and distinguishing these cells correctly requires the additional use of markers that are specific to $\mathrm{m} \phi$, such as CD64 (Fc $\gamma R \mathrm{RI}), \mathrm{F} 4 / 80$ or Mer tyrosine kinase (MerTK) ${ }^{2,4-6}$ Initial ideas that CD103 (integrin $\alpha_{\mathrm{E}}$ ) and CX3CR1 (fractalkine receptor) could be used to identify intestinal $\mathrm{CDC}$ and $\mathrm{m} \phi$ respectively, have also proved incorrect, as it is now clear that not all cDC in the intestine express CD103 and that some also express CX3CR1.

Intestinal LP $\mathrm{cDC}$ can be identified as lineage (CD3, CD19, B220, NK1.1, CD64)-negative cells that express CD11c and MHCII (Table 1; Figure 1a,b). ${ }^{7,8}$ In compliance with the current definition of $\mathrm{cDC}$ these cells express FMS-like tyrosine kinase 3 (FLT3/CD135), the receptor for the CDC-specific growth factor FLT3 ligand (FLT3L) and show dependence on this receptor-ligand pathway for their development from cDC precursors in the bone marrow (BM) ${ }^{8,9}$ They also express the zinc finger and BTB domain containing 46 (Zbtb46) transcription factor (TF) ${ }^{8,10}$ have a lifespan in the tissue of only a few days, and have the capacity to migrate in afferent lymph to the draining lymph nodes, where they can prime naive T cells. ${ }^{2,3,5}$ In contrast, cells of the monocyte-m $\phi$ lineage are $\mathrm{CD} 64^{+} \mathrm{CD} 11 \mathrm{~b}{ }^{+}$(Table 2; Figure 1a,d), independent of FLT3 signaling, but require the colony-stimulating factor 1 receptor (CSF-1R/CD115) for development. ${ }^{11}$ They are derived from monocytes or embryonic stem cells, and in steady state they have a lifespan of several weeks in tissues, do not migrate in lymph and have little or no ability to prime naive $\mathrm{T}$ cells. ${ }^{2,4}$ Wherever possible, we will discuss intestinal $\mathrm{cDC}$ and $\mathrm{m} \phi$ that have been identified based on these parameters, but caution needs to be used when interpreting the many studies in the field that have not applied such rigorous strategies.

\section{PART A. INTESTINAL cDC}

While Peyer's patches (PP) contain a sizeable population of $\mathrm{cDC}$, the current review focuses on those $\mathrm{CDC}$ that are diffusely

${ }^{1}$ Section of Immunology and Vaccinology, Danish Technical University Veterinary Institute, Copenhagen, Denmark. ${ }^{2}$ Section of Immunology, Department of Experimental Medical Science, Lund University, Lund, Sweden and ${ }^{3}$ Centre for Immunobiology, Institute of Infection, Immunity and Inflammation, University of Glasgow, Glasgow, Scotland, UK. Correspondence: W Agace (william.agace@med.lu.se) or A Mowat (Allan.Mowat@glasgow.ac.uk).

${ }^{4}$ These authors share first authorship of this manuscript.

${ }^{5}$ These authors contributed equally to this work.

Received 28 October 2016; accepted 22 February 2017; published online 5 April 2017. doi:10.1038/mi.2017.22 
Table 1 Conventional DC subsets in the intestine

\begin{tabular}{|c|c|c|c|c|c|c|c|c|c|}
\hline \multicolumn{3}{|c|}{ Phenotype } & \multicolumn{3}{|c|}{ Ontogeny } & \multicolumn{2}{|c|}{ Function } & \multicolumn{2}{|c|}{ Abundance } \\
\hline Common & & bset-specific & GF & & nvolvement & Common Functions & Specialized Functions & siLP & coLP \\
\hline 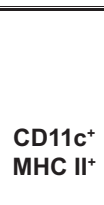 & $\underset{\substack{\frac{\alpha}{0} \\
x}}{+}$ & $\begin{array}{c}\text { CD103 }^{+} \\
\text {CD11b }^{-} \\
\text {CX3CR1 }^{\text {neg }}\end{array}$ & \multirow{3}{*}{ 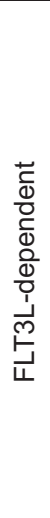 } & \multirow{3}{*}{$\begin{array}{l}\stackrel{\bullet}{+} \\
\stackrel{\infty}{\mathscr{m}} \\
\stackrel{N}{N}\end{array}$} & $\begin{array}{c}\text { IRF8 } \\
\text { BatF3 } \\
\text { ID2 }\end{array}$ & \multirow{3}{*}{$\begin{array}{l}\text { - CCR7-dependent } \\
\text { migration to intestine } \\
\text { draining lymph nodes } \\
\text { - Presentation of } \\
\text { soluble protein } \\
\text { antigens }\end{array}$} & $\begin{array}{ll}\text { - } & \text { Th1 } \\
\text { - } & \text { Cross presentation } \\
\text { - } & \text { Induction of CD } 8 \alpha \beta^{+} \text {and } \\
& \text { CTL-like CD } 8 \alpha \alpha^{+} \mathrm{CD} 4^{+} \text {IEL } \\
\text { - } & \text { Predominant in CCR } 9 / \alpha_{4} \beta_{7} \\
& \text { induction }\end{array}$ & + & ++ \\
\hline $\begin{array}{l}\mathrm{CD}^{-} 4^{-} \\
\mathrm{F}^{-} / 80^{-} \\
\text {MerTK}^{-} \\
\text {Ly6C- }^{-} \\
\text {CD3- }^{-} \\
\text {CD19- }\end{array}$ & \multirow{2}{*}{$\frac{+}{8}$} & $\begin{array}{c}\text { CD103 }^{+} \\
\text {CD11 }^{+} \\
\text {CX3CR1 1ow }\end{array}$ & & & $\begin{array}{c}\text { IRF4 } \\
\text { KLF4 } \\
\text { Notch2 }\end{array}$ & & $\begin{array}{ll}\text { - Th17 } \\
\text { - Th2 } \\
\text { - ILC3 activation }\end{array}$ & +++ & + \\
\hline $\begin{array}{l}\text { B220- } \\
\text { NK1.1- }\end{array}$ & & $\begin{array}{c}\mathrm{CD}^{103^{-}} \\
\text {CD11 }^{+} \\
\text {CX3CR1 }^{\text {int }}\end{array}$ & & & $\begin{array}{l}\text { Zeb2 } \\
\text { IRF4 } \\
\text { Notch2? } \\
\text { KLF4? }\end{array}$ & & $\begin{array}{l}\text { - Th1 priming } \\
\text { - Th2 priming } \\
\text { - Th17 priming } \\
\text { - ILC3 activation? }\end{array}$ & + & +++ \\
\hline
\end{tabular}

Abbreviation: coLP, colonic lamina propria; GF, growth factors; siLP, small intestinal lamina propria; TF, transcription factors.

Summary of the phenotypic markers, ontogeny, key functions and relative abundance of intestinal cDC subsets.

distributed throughout the intestinal LP. It should, however, be noted that intestinal LP cell preparations will contain CDC from 'contaminating' isolated lymphoid follicles. As the major antigen-presenting cells of the immune system, intestinal cDC continually sample their environment for foreign (food proteins, microbes) and self-antigens. ${ }^{12-18}$ In addition to uptake of apoptotic or damaged cells, several mechanisms have been proposed for how intestinal $\mathrm{CDC}$ acquire antigen from the lumen including the extension of trans-epithelial dendrites into the lumen, ${ }^{19}$ via goblet cell-associated antigenpassages ${ }^{20,21}$ indirectly via villus $\mathrm{M}$ cells, ${ }^{22}$ or after transfer from tissue-resident $\mathrm{m} \phi .^{23}$ Some soluble materials may also be taken up by cDC after crossing the epithelium by paracellular or transcellular mechanisms. ${ }^{24}$ After acquiring antigen, cDC migrate in a chemokine receptor 7 (CCR7) dependent manner via afferent lymphatics to intestinal-draining mesenteric lymph nodes (MLN), where they present processed antigen to cells of the adaptive immune system. ${ }^{15,17,18,25-26} \mathrm{~T}$ cells activated in MLN are induced to express a 'gut homing' CCR9 ${ }^{+} \alpha_{4} \beta_{7}^{+}$ phenotype, ${ }^{27,28}$ in part through the action of retinoic acid (RA) derived from migratory intestinal $\mathrm{cDC}$ and/or local stromal cells. ${ }^{25,29-31}$ In the steady state, intestinal cDC are considered to be tolerogenic, a property that appears to be maintained, at least in part through MAP kinase $\mathrm{p} 38 \alpha,{ }^{32}$ transforming growth factor $\beta$ receptor II (TGF $\beta$ RII) signaling, ${ }^{33}$ tumor necrosis factor receptor-associated factor 6 (TRAF6), ${ }^{34}$ $\beta$-catenin signaling, ${ }^{35}$ as well as the signaling regulator A20 (TNFAIP3). ${ }^{36,37}$ In this state, presentation of innocuous antigens by CDC promotes the generation of forkhead box $\mathrm{P}^{+}\left(\mathrm{FoxP}^{+}\right)$inducible regulatory $\mathrm{T}$ cells $\left(\mathrm{iT}_{\text {reg }}\right)$ in MLN and is key to the development of oral tolerance to dietary proteins and for maintaining the symbiotic relationship with the microbiota. ${ }^{18,38-40}$ Intestinal $\mathrm{cDC}$ also express a wide array of cytokine and pattern recognition receptors, allowing them to respond to local inflammatory cues and microbial products and so to initiate active immunity when necessary. Notably the various individual subsets of intestinal $\mathrm{cDC}$ (see below) are equipped with distinct combinations of pattern recognition receptors, and thus may respond to microbes in different ways. ${ }^{41-47}$

\section{PHENOTYPE AND ONTOGENY OF INTESTINAL CDC SUBSETS}

Intestinal $\mathrm{cDC}$ are highly heterogeneous and recent years have seen great progress in our understanding of intestinal cDC subset development and functions. Although early work assumed that intestinal $\mathrm{cDC}$ comprised a homogeneous population of $\mathrm{CD} 103^{+}$cells, this is now known to be an over-simplification and most recent studies have divided them on the basis of CD103 and CD11b expression. This reveals three

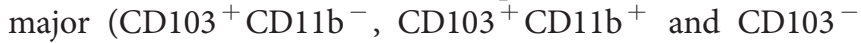

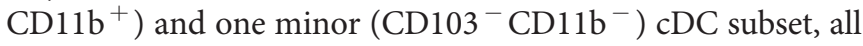
of which express the TF Zbtb46, are dependent on FLT3L for development in vivo and are derived from a pre-cDC precursor. ${ }^{8,10,13}$ Importantly all four populations of $\mathrm{CD} 103^{+}$ $\mathrm{CD}_{11} \mathrm{~b}^{-}, \mathrm{CD}_{103}{ }^{+} \mathrm{CD} 11 \mathrm{~b}^{+}, \mathrm{CD} 103^{-} \mathrm{CD}_{11}{ }^{+}, \mathrm{CD}_{103}{ }^{-}$ $\mathrm{CD}_{11 \mathrm{~b}^{-}}$intestinal $\mathrm{cDC}$ can be found in the migratory compartment of intestine draining LN, as well as in pseudo-afferent lymph draining the steady state intestine. ${ }^{8,10,13,14}$ Thus each has the potential of initiating and regulating adaptive immune responses within $\mathrm{LN}$.

Apart from $\mathrm{CD}_{103}{ }^{-} \mathrm{CD} 11 \mathrm{~b}^{-} \mathrm{cDC}$, all the other $\mathrm{cDC}$ subsets are present in the intestinal-draining lymph of RA-receptor related orphan receptor $\gamma t$ deficient mice $\left(\right.$ Rorc $\left.^{-I-}\right)$, which lack isolated lymphoid follicles and $\mathrm{PP},{ }^{13}$ suggesting that they derive from the LP. Since the minor population of $\mathrm{CD}_{103}{ }^{-} \mathrm{CD} 11 \mathrm{~b}^{-} \mathrm{DC}$ appears heterogeneous and its functions are unknown, it will not be discussed further here. 
a

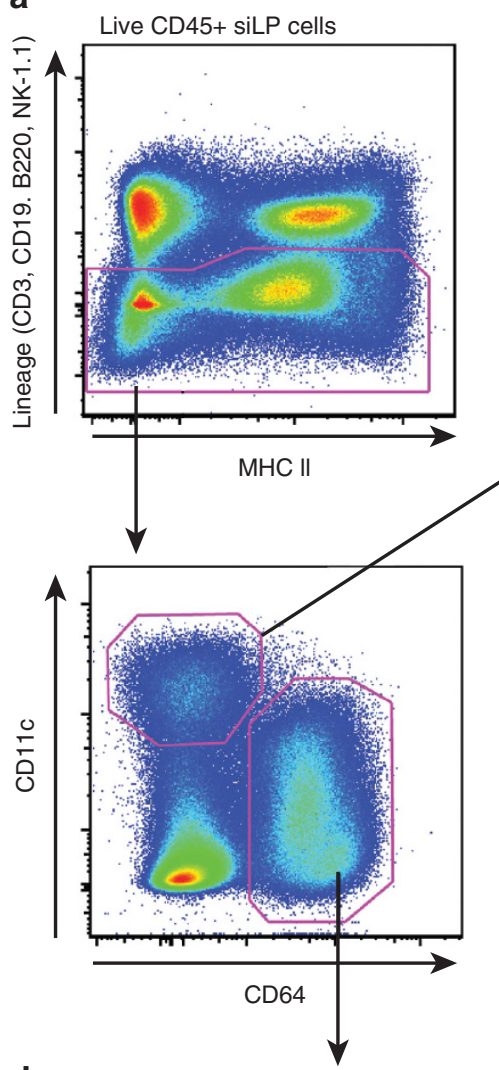

d

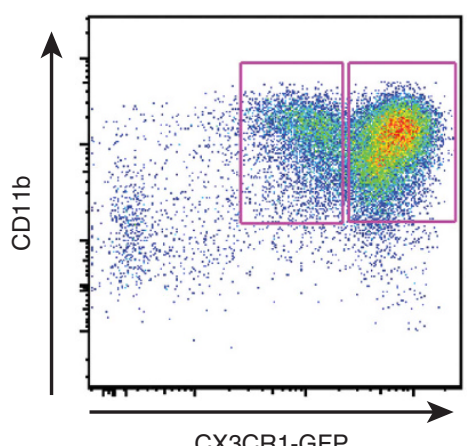

b
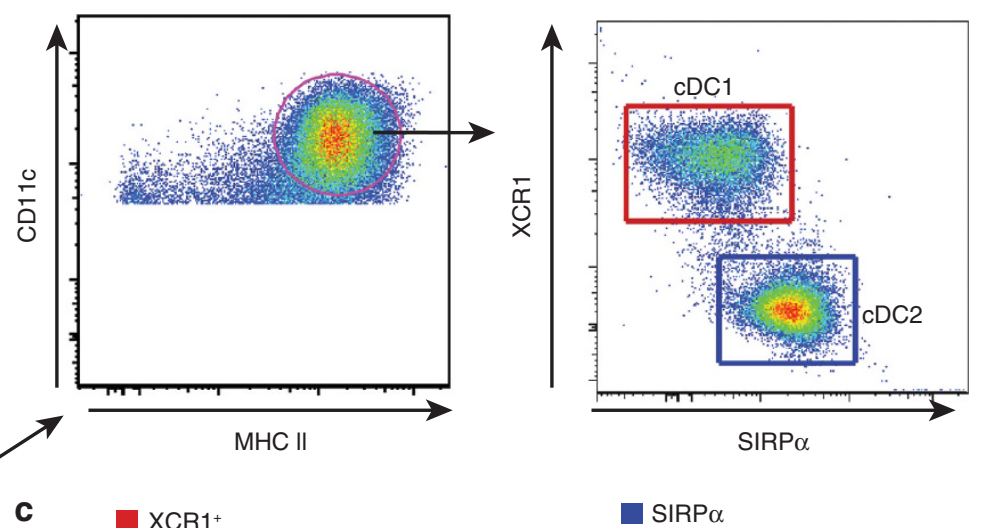

C $\quad \mathrm{XCR} 1$

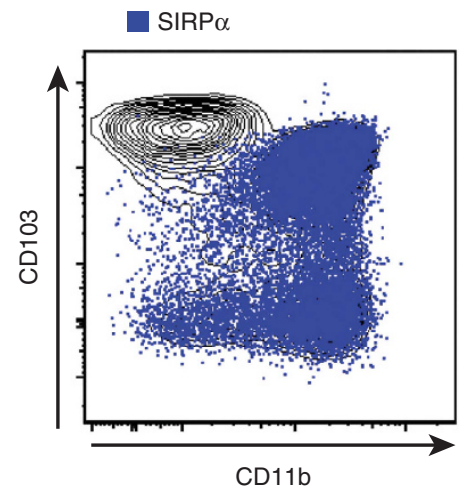

CD11b
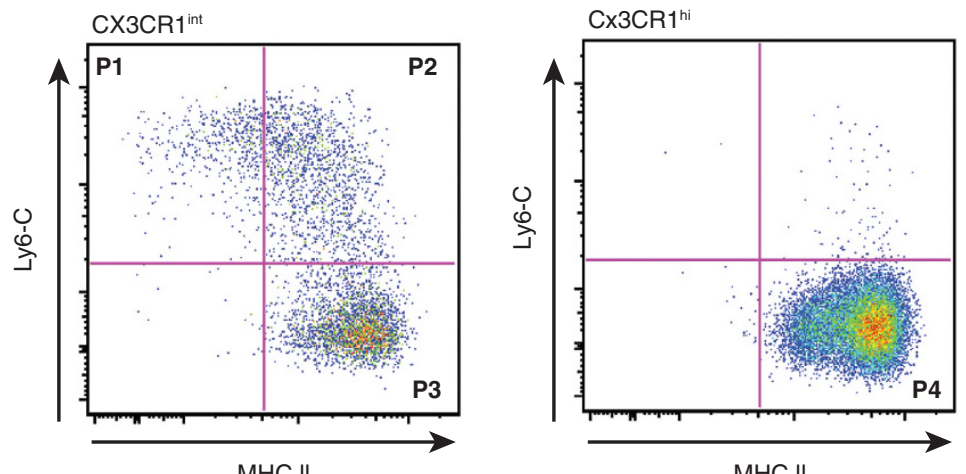

Figure 1 Identification of intestinal MNP subsets by flow cytometry. Representative analysis of small intestinal LP cells pre-gated on live CD45 ${ }^{+}$cells. (a) Following exclusion of lineage (CD3, CD19, B220, NK-1.1), cells of the monocyte/m $\phi$ lineage are identified as CD64 ${ }^{+}$, whereas cDC fall into the $\mathrm{CD} 11 \mathrm{c}^{\text {hi }} \mathrm{CD} 64^{-}$fraction. (b) Bona fide $\mathrm{CDC}$ are further characterized by high expression of MHCII and can be divided into XCR1 ${ }^{+}$and SIRP $\alpha^{+}$ subsets. (c) $X C R 1{ }^{+} \mathrm{CDC}$ are almost entirely $\mathrm{CD} 103^{+} \mathrm{CD} 11 \mathrm{~b}^{-}$, whereas SIRP $\alpha^{+} \mathrm{CDC}$ are heterogeneous and comprise $\mathrm{CD} 103^{+} \mathrm{CD} 11 \mathrm{~b}{ }^{+}$and $\mathrm{CD}_{103}{ }^{-} \mathrm{CD} 11 \mathrm{~b}^{+} \mathrm{CDC}$, together with a minor population of $\mathrm{CD} 103^{-} \mathrm{CD} 11 \mathrm{~b}^{-} \mathrm{CDC}$. (d) Using $\mathrm{C} \times 3 \mathrm{cr} 1^{\mathrm{GFP} /+}$ reporter mice, the monocyte/m $\phi$ lineage can be subdivided into $\mathrm{CD} 11 \mathrm{~b}^{+} \mathrm{CX} 3 \mathrm{CR} 1^{\text {int }}$ cells and $\mathrm{CD} 11 \mathrm{~b}^{+} \mathrm{CX} 3 \mathrm{CR} 1^{\text {hi }}$ cells. The $\mathrm{CD} 11 \mathrm{~b}^{+} \mathrm{CX} 3 \mathrm{CR} 1^{\text {int }}$ cells contain a mixture of monocytes and $\mathrm{m} \phi$ precursors, which can be further classified into a "monocyte waterfall" as $\mathrm{Ly} 6 \mathrm{C}^{\text {hi }} \mathrm{MHCII}{ }^{-}$recently recruited monocytes $(\mathrm{P} 1)$, $\mathrm{Ly} 6 \mathrm{C}^{\text {hi}} \mathrm{MHClI}{ }^{+}$maturing

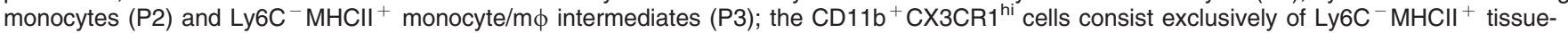
resident $\mathrm{m} \phi$. cDC, conventional dendritic cells; LP, lamina propria; MNP, mononuclear phagocyte; SIRP $\alpha$, signal regulatory protein $\alpha$; XCR1, X-C motif chemokine receptor 1 .

The proportions of $\mathrm{CD}_{103}{ }^{+} \mathrm{CD} 11 \mathrm{~b}^{-}, \mathrm{CD} 103^{+} \mathrm{CD} 11 \mathrm{~b}^{+}$, $\mathrm{CD}_{103}{ }^{-} \mathrm{CD} 11 \mathrm{~b}^{+}$LP cDC differ markedly along the length of the intestine. For example, $\mathrm{CD}_{103}{ }^{+} \mathrm{CD}_{11 \mathrm{~b}}{ }^{+} \mathrm{cDC}$ make up the major proportion of $\mathrm{CDC}$ in the small intestine, but constitute only a minor fraction of $\mathrm{cDC}$ in the colon, where $\mathrm{CD} 103{ }^{+} \mathrm{CD}_{11 \mathrm{~b}}{ }^{-} \mathrm{cDC}$ predominate. ${ }^{48,49}$ While these differences may reflect the distinct physiological requirements of these tissues and variations in the environmental conditioning factors present in each site (see below), the functional consequences remain to be explored.

Parallel studies have demonstrated that $\mathrm{CDC}$ across tissues can be split into two major branches of X-C motif chemokine receptor 1 (XCR1) or signal regulatory protein $\alpha$ (SIRP $\alpha /$ CD172a) expressing cDC. Such studies have resulted in a unifying nomenclature for XCR $1^{+} \mathrm{CDC}$ as $\mathrm{CDC} 1$ and SIRP $\alpha^{+}$ cDC as cDC2. ${ }^{9,41,50}$ Murine $\mathrm{CDC} 1$, but not $\mathrm{cDC} 2$, are dependent 
on the TFs interferon regulatory factor 8 (IRF8), basic leucine rich zipper transcription factor ATF-like 3 (BATF3) and inhibitor of DNA-binding 2 (ID2) for their development, while absence of the TFs IRF4, neurogenic locus notch homolog protein 2 (NOTCH2), RelB and Krüppel-like factor 4 (KLF4) impacts negatively on the development of CDC2 (see article by Sichien et $a l^{51}$ ). XCR1 and SIRP $\alpha$ expression also splits the murine intestinal $\mathrm{CDC}$ compartment into two major populations. Intestinal XCR1 ${ }^{+} \mathrm{cDC}$ are almost entirely $\mathrm{CD} 103^{+}$ $\mathrm{CD}_{11 \mathrm{~b}}{ }^{-}$, with a very minor population being $\mathrm{CD}_{103}{ }^{-}$ $\mathrm{CD}_{11 \mathrm{~b}}{ }^{-}$(Figure $\mathbf{1 b}$ and $\mathbf{c}$ ). As with extra-intestinal $\mathrm{XCR}^{+}{ }^{+} \mathrm{cDC}$, intestinal $\mathrm{CD} 103^{+} \mathrm{CD} 11 \mathrm{~b}^{-} \mathrm{cDC}$ express IRF8, ${ }^{7}$ and their generation is dependent on the TFs IRF8, ID2 and BATF3. ${ }^{7,12,52,53}$ Of note, mice that are haploinsufficient in $\operatorname{Irf} 8$ have normal numbers of intestinal and migratory $\mathrm{CD}_{103}{ }^{+} \mathrm{CD}_{11 \mathrm{~b}}{ }^{-} \mathrm{CDC}$ in MLN, but severely reduced numbers of $\mathrm{MLN}$ resident $\mathrm{XCR} 1^{+} \mathrm{CDC}$, indicating some differences in IRF8 dependency between XCR1 ${ }^{+} \mathrm{cDC}$ populations. ${ }^{7}$ Intestinal SIRP $\alpha{ }^{+} \mathrm{cDC}$ are more heterogeneous and include major populations of $\mathrm{CD}_{103}{ }^{+} \mathrm{CD}_{11 \mathrm{~b}}{ }^{+}$and $\mathrm{CD}_{103}{ }^{-} \mathrm{CD}_{11 \mathrm{~b}^{+}} \mathrm{cDC}$, together with a small group of CD $103^{-} \mathrm{CD}_{11 b^{-}} \mathrm{cDC}$ (Figure 1b and c). CD11c-targeted deletion in Irf4 leads to a partial reduction of CD103 ${ }^{+} \mathrm{CD} 11 \mathrm{~b}^{+}$ cDC in the small intestinal LP and an absence of these cells in the $\mathrm{MLN}^{54}$ as well as reduced numbers of CCR2 expressing $\mathrm{CD}_{103}{ }^{-} \mathrm{CD}_{11 \mathrm{~b}}{ }^{+}$DCs. ${ }^{8}$ Further, mice whose $\mathrm{CD} 11 \mathrm{c}^{+}$cells are deficient in Notch 2 display reduced numbers of $\mathrm{CD} 103^{+}$ $\mathrm{CD}_{11 \mathrm{~b}}{ }^{+} \mathrm{cDC}$ in the small intestine and MLN, ${ }^{10,55}$ while deficiency in Klf4 results in reduced proportions of small intestinal $\mathrm{CD}_{103}{ }^{+} \mathrm{CD}_{11 \mathrm{~b}}{ }^{+} \mathrm{cDC}$, as well as both migratory and $\mathrm{LN}$-resident $\operatorname{SIRP} \alpha^{+} \mathrm{cDC}$ in MLN. ${ }^{56}$ Whether intestinal $\mathrm{CD}_{103}{ }^{-} \mathrm{CD} 11 \mathrm{~b}^{+} \mathrm{cDC}$ numbers are also altered in the absence of Klf4 or Notch2 remains to be determined using rigorous gating strategies. ${ }^{10,55}$ It also remains unclear whether, and at what point, these TFs interact to regulate $\mathrm{CD} 103^{+} \mathrm{CD} 11 \mathrm{~b}{ }^{+}$ cDC development. Finally mice with deficiency of Zinc finger E-box-binding homeobox TF 2 (Zeb2) in CD11c ${ }^{+}$cells show a reduced proportion of $\mathrm{CD}_{103}{ }^{-} \mathrm{CD}_{11} \mathrm{~b}^{+} \mathrm{CDC}$ within the intestine but not MLN, together with normal proportions of intestinal and $\mathrm{MLN} \mathrm{CD} 103^{+} \mathrm{CD}_{11 \mathrm{~b}}{ }^{+} \mathrm{cDC}$, although the absolute number of each of these SIRP $\alpha{ }^{+}$cDC subsets was not assessed. $^{57}$

In preliminary studies we have found that the transcriptomes of small intestinal $\mathrm{CD}_{103}{ }^{-} \mathrm{CD}_{11 b^{+}}$and $\mathrm{CD}_{103}{ }^{+} \mathrm{CD}_{11 \mathrm{~b}}{ }^{+}$ cDC differ by only 100-200 genes and that absence of TGF $\beta R$ I signaling in CD11 $\mathrm{c}^{+}$cells leads to a marked reduction in small intestinal $\mathrm{CD}_{103}{ }^{+} \mathrm{CD}_{11 \mathrm{~b}^{+}} \mathrm{cDC}$ and a concomitant accumulation of $\mathrm{CD} 03^{-} \mathrm{CD}_{11 \mathrm{~b}}{ }^{+} \mathrm{cDC}$ (Montgomery, C.C. Bain, J. Montgomery, C.L. Scott, J.M. Kel, M.J.H. Girard-Madoux, L. Marten et al., unpublished data). Collectively these findings indicate that these subsets are closely related to one another and that steady state TGF $\beta R$ signaling drives the differentiation of at least some CD103$\mathrm{CD}_{11 \mathrm{~b}}{ }^{+} \mathrm{cDC}$ into CD $103^{+} \mathrm{CD} 11 \mathrm{~b}^{+} \mathrm{cDC}$. Nevertheless given the heterogeneity in phenotype, TF requirements and function of intestinal SIRP $\alpha^{+} \mathrm{cDC}$, we refer to these intestinal $\mathrm{cDC}$ populations below as $\mathrm{XCR} 1^{+}$or $\operatorname{SIRP} \alpha^{+} \mathrm{cDC}$, rather than cDC1 and cDC2.

\section{FUNCTIONS OF INTESTINAL CDC SUBSETS Non-redundant functions of intestinal XCR1 ${ }^{+} \mathrm{CDC}$}

Several mouse models have been utilized to draw conclusions on the in vivo function of intestinal XCR1 ${ }^{+} \mathrm{cDC}$, including Batf $^{-1-}$, and more recently Cd11c-cre.Irf $8^{\mathrm{fl} / \mathrm{fl}}$, Zbtb46cre.Irf $8^{\mathrm{fl} / \mathrm{fl}}, X c r 1$-DTA and Clec9a-DTR mice. ${ }^{7,38,45,52,58}$ While each of these models results in a marked or complete depletion of intestinal XCR1 ${ }^{+} \mathrm{cDC}$, findings from these studies should be taken with a degree of caution, as direct effects on additional cell types have often not been ruled out. It can also be unclear whether the consequences of deletion reflect absence of XCR ${ }^{+}$ cDC in the intestine or other tissues. Nevertheless, these models have greatly extended our understanding of the biological function of XCR1 ${ }^{+} \mathrm{cDC}$ and demonstrate that they play key non-redundant roles in regulating multiple aspects of the intestinal immune response.

Cd11c-cre.Irf $8^{\mathrm{fl} / \mathrm{fl}}$ and Xcr1-DTA mice have reduced numbers of $\mathrm{CD}^{+}$and $\mathrm{CD} 8^{+}$LP T cells and conventional $\mathrm{CD} 8 \alpha \beta^{+} \mathrm{TCR} \alpha \beta^{+}$and unconventional $\mathrm{CD} 8 \alpha \alpha^{+} \mathrm{TCR} \alpha \beta^{+}$ and $\mathrm{CD} 8 \alpha \alpha^{+} \mathrm{TCR} \gamma \delta^{+}$intra-epithelial lymphocytes in the small intestine. ${ }^{7,58}$ Several mechanisms by which XCR1 ${ }^{+} \mathrm{cDC}$ potentially support small intestinal $\mathrm{T}$-cell homeostasis have been identified. First small intestine-derived $\mathrm{CD}_{103}{ }^{+} \mathrm{CD} 11 \mathrm{~b}^{-}$ CDC in MLN appear to be the major source of $\mathrm{CDC}$-derived $\mathrm{RA},{ }^{7}$ a key inducer of CCR9 and $\alpha_{4} \beta_{7}$ on responding T cells, and their absence results in a reduced generation of CCR9 ${ }^{+}$ $\alpha_{4} \beta_{7}^{+}$small intestinal homing T cells. ${ }^{7}$ Second, XCR1 ${ }^{+}$DC play a dominant role in cross-presenting intestinal epitheliumderived cell-associated antigen to $\mathrm{CD}^{+} \mathrm{T}$ cells in steady state, ${ }^{14}$ and are required for optimal CD8 ${ }^{+}$T-cell responses to orally administered protein antigen and rotavirus infection. ${ }^{7,59}$ Thus reduced $\mathrm{CD} 8^{+} \mathrm{T}$-cell priming may contribute to reduced numbers of small intestinal CD $8 \alpha \beta^{+} \mathrm{T}$ cells. Finally, XCR1 and XCL1 deficient mice also display a selective reduction in small intestinal TCR $\alpha \beta^{+}$T cells. Here, crosstalk between XCR1 on intestinal $\mathrm{CD}_{103}{ }^{+} \mathrm{CD}_{11 \mathrm{~b}}{ }^{-} \mathrm{cDC}$ - and XCL1-expressing $\mathrm{T}$ cells appears to promote intestinal T-cell survival as well as modulate $\mathrm{CD} 103^{+} \mathrm{CD} 11 \mathrm{~b}^{-} \mathrm{cDC}$ maturation, promoting their migration to the MLN. ${ }^{58}$

Intestinal XCR1 ${ }^{+} \mathrm{cDC}$ are also required for the generation and maintenance of particular intestinal $\mathrm{CD} 4{ }^{+} \mathrm{T}$-cell subsets. Small intestinal CD $4^{+}$T cells in Xcr1-DTA mice have reduced levels of IFN- $\gamma$ mRNA ${ }^{58}$ and the small intestine and colon LP of Cd11c-cre.Irf $8^{\mathrm{fl} / \mathrm{fl}}$ mice have a dramatic reduction in Th1 cells. ${ }^{7}$ These mice also fail to generate colonic Th1 responses to the colonic-dwelling protozoan Trichomonas musculis. ${ }^{60}$ One explanation for the reduction in intestinal Th1 cells in the absence of XCR1 ${ }^{+}$cDC is defective Th1 cell generation in MLN. ${ }^{7}$ While the mechanisms underlying this defect remain to be determined, one possibility is that a loss of XCR1 ${ }^{+} \mathrm{cDC}$ results in reduced levels of IL-12. Consistent with this idea, $\mathrm{CD} 103^{+} \mathrm{CD}_{11 \mathrm{~b}}{ }^{-} \mathrm{cDC}$ are the major cDC source of IL-12 in the MLN in the steady state ${ }^{61}$ and during acute graft versus host 
disease. ${ }^{62}$ Further IL-12 production by $\mathrm{CD} 103^{+} \mathrm{CD} 11 \mathrm{~b}^{-} \mathrm{cDC}$ is required for driving IFN- $\gamma$ production in $\mathrm{T}$ and NK cells during Toxoplasma gondii infection, ${ }^{63}$ while IL-12 and IL-15 production by colonic $\mathrm{CD} 103^{+} \mathrm{CD}_{11 \mathrm{~b}^{-}} \mathrm{cDC}$ has been implicated in driving tonic release of IFN- $\gamma$ by intestinal $\mathrm{T}$ cells, promoting epithelial resistance to dextran sodium sulphate (DSS)-induced colitis. ${ }^{45}$ Of note, deletion of the A20 inhibitor of nuclear factor- $\mathrm{\kappa B}$ activation in $\mathrm{CD} 11 \mathrm{c}$-expressing cells leads to upregulation of the co-stimulatory molecules CD80 and $\mathrm{CD} 86$ on $\mathrm{CD}_{103}{ }^{+} \mathrm{CD}_{11 \mathrm{~b}}{ }^{-} \mathrm{cDC}$ and unleashes their ability to drive massive IFN- $\gamma$ production by $\mathrm{CD} 4^{+} \mathrm{T}$ cells. Therefore in the steady state this signal attenuator may normally limit the capacity of XCR $1^{+} \mathrm{cDC}$ to drive Th1 cell differentiation. ${ }^{37}$

Cd11c-cre.Irf $8^{\mathrm{f} / \mathrm{fl}}, \mathrm{Xcr} 1$-DTA and Batf $3^{-I-}$ mice also lack $\mathrm{CD} 4{ }^{+} \mathrm{CD} 8 \alpha \alpha^{+}$intra-epithelial lymphocytes, ${ }^{7,58,64}$ a population of MHCII-restricted cytotoxic T cells whose development from conventional $\mathrm{CD}^{+} \mathrm{T}$ cells requires TGF $\beta$ and RA. ${ }^{65,66} \mathrm{We}$ recently demonstrated that this process also requires $\mathrm{CD} 103^{+}$ $\mathrm{CD}_{11 \mathrm{~b}}{ }^{-}$cDC expression of the $\alpha_{v} \beta_{8}$ integrin, ${ }^{7}$ involved in the activation of the latent TGF $\beta$ complex. ${ }^{67}$ Interaction between cell adhesion molecule 1 (CADM1) on intestinal $\mathrm{CD} 103^{+} \mathrm{CD}_{11 \mathrm{~b}}{ }^{-}$ CDC and class 1-restricted T-cell adhesion molecule (CRTAM) on intestinal $\mathrm{CD} 4^{+} \mathrm{T}$ cells has also been implicated in the generation of $\mathrm{CD} 4{ }^{+} \mathrm{CD} 8 \alpha \alpha^{+}$intra-epithelial lymphocytes, ${ }^{64}$ although intestinal $\mathrm{m} \phi$ also express CADM1 (based on IMMGEN.org database and authors unpublished observation) and so could also contribute to local differentiation of this population.

Finally, $\mathrm{CD}_{103}{ }^{+} \mathrm{CD}_{11 \mathrm{~b}}{ }^{-} \mathrm{cDC}$ are required for the optimal generation of $\mathrm{iT}_{\text {reg }}$ in MLN following oral administration of protein antigen. ${ }^{38}$ This could reflect the high capacity of $\mathrm{CD} 103^{+}$

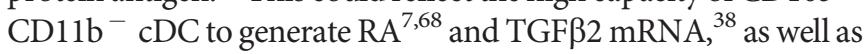
their expression of the highest levels of $\alpha_{v} \beta_{8}$ integrin amongst intestinal $\mathrm{cDC},{ }^{7,38,69}$ all factors that are associated with $\mathrm{iT}_{\mathrm{reg}}$ conversion. However the overall significance of these findings remains to be elucidated, as mice deficient in $\mathrm{XCR}^{+}{ }^{+} \mathrm{cDC}$ display normal proportions of endogenous FoxP3 ${ }^{+} \mathrm{T}_{\text {reg }}$ in the intestine $^{7,52,58,70,71}$ and develop oral tolerance normally. ${ }^{38}$

\section{Non-redundant functions of SIRP $\alpha^{+}$CDC subsets}

Models that have been utilized to draw conclusions on the in vivo functions of SIRP $\alpha^{+}$cDC include Cd11c-cre.Irf4 $4^{\mathrm{fl} / \mathrm{fl}}, 54,72$ Cd11c-cre.Notch2 $2^{\mathrm{fl} / \mathrm{fl} 1},{ }^{10,55}$ Cd11c-cre.Klf4 ${ }^{\mathrm{fl} / \mathrm{fl}, 56}$ Clec4a4-DTR ${ }^{45}$ and $\operatorname{Sirp\alpha ^{-1-}}$ mice $^{73}$; as well as huLangerin-DTA mice that express Diphtheria toxin A (DTA) under the control of the human Langerin promoter, which is primarily active in intestinal $\mathrm{CD} 03^{+} \mathrm{CD} 1 \mathrm{~b}^{+} \mathrm{cDC}^{71}$ Notably, none of the above models show depletion in all intestinal SIRP $\alpha^{+} \mathrm{cDC}$. Further it is important to bear in mind that changes in immunological responses observed in mice with CD11c-Cremediated deletion of Irf4, Notch 2 or Klf4 may not necessarily be due to depletion of a particular SIRP $\alpha^{+}$cDC subset, but could reflect an impact on cDC function. Of further note, as our understanding of MNP subsets has advanced, it remains possible that functions ascribed previously to cells of the monocyte-m $\phi$ lineage through the use of for example $C \mathrm{cr} 2^{-1-}$ and $C \times 3 c r 1-D T R$ mice may in fact be a function of SIRP $\alpha^{+}$
CDC, as some of these cells express CCR2 and intermediate levels of CX3CR1; the numbers of several SIRP $\alpha^{+}$cDC subsets are also markedly reduced in these animals. ${ }^{8,74}$

Cd11c-cre.Irf4 ${ }^{\mathrm{l} / \mathrm{fl}}$, Cd11c-cre.Notch2 $2^{\mathrm{f} / \mathrm{fl}}$ and Sirp $\alpha^{-1-}$ mice display a selective reduction in intestinal Th17 cells, ${ }^{54,55,72-73}$ collectively suggesting a key role for SIRP $\alpha^{+}$cDC in intestinal Th17 cell homeostasis. Cd11c-cre.Irf $4^{\mathrm{f} / \mathrm{fl}}$ mice also fail to generate colonic Th17 responses to Trichomonas musculis. ${ }^{60}$ Further, huLangerin-DTA mice have reduced numbers of small intestinal Th17 cells, suggesting that loss of $\mathrm{CD} 103^{+} \mathrm{CD} 11 \mathrm{~b}^{+}$ cDC underlies Th17 deficiency at this site, although MHCII expression by these cells may not be required. ${ }^{71}$

While the mechanisms underlying reduced intestinal Th17 cell numbers in the above models remains unclear, one likely contributing factor is reduced Th17 differentiation in intestinal-draining lymph nodes. Thus Cd11c-cre.Irf $4^{\mathrm{fl} / \mathrm{fl}}$ mice fail to support Th17 differentiation in MLN following immunization with antigen and adjuvant. ${ }^{54}$ Mechanistically, Th17 priming under these conditions is IL- 6 dependent and absence of small intestinal-derived migratory $\mathrm{CD} 103^{+} \mathrm{CD}_{11 \mathrm{~b}}{ }^{+} \mathrm{cDC}$ in MLN of $C d 11 c$-cre.Irf $4^{\mathrm{f} / \mathrm{fl}}$ mice leads to reduced levels of cDC-derived IL-6. ${ }^{54}$ Consistent with these findings small intestinal LP $\mathrm{CD}_{103}{ }^{+} \mathrm{CD} 11 \mathrm{~b}^{+} \mathrm{cDC}$ but not $\mathrm{CD} 103^{+} \mathrm{CD}_{11 \mathrm{~b}}{ }^{-} \mathrm{cDC}$ from Cd11c-cre. $A 20^{\mathrm{f} / / \mathrm{l}}$ mice spontaneously produce large amounts of IL-6 and drive IL-6-dependent Th17 differentiation in vitro. ${ }^{37}$

Recent studies have also shown that $\mathrm{CD} 103^{-} \mathrm{CD} 11 \mathrm{~b}^{+} \mathrm{cDC}$, and in particular $\mathrm{CCR} 2{ }^{+} \mathrm{CD} 103^{-} \mathrm{CD} 11 \mathrm{~b}^{+} \mathrm{CDC}$, are capable of driving Th17 cell differentiation in vitro. ${ }^{8,75}$ Since CD103 ${ }^{-}$ $\mathrm{CD} 1 \mathrm{~b}^{+}{ }_{\mathrm{cDC}}$ are the dominant SIRP $\alpha^{+} \mathrm{cDC}$ in the colon and colon-draining nodes, ${ }^{49}$ it remains plausible that these cells play an important role in colonic Th17 cell homeostasis, although this remains to be addressed experimentally. Interestingly Cd11c-cre.Klf4 ${ }^{\mathrm{fl} / \mathrm{fl}}$ mice, that also have reduced numbers of intestinal SIRP $\alpha^{+} \mathrm{CDC}$ appear capable of mounting normal intestinal Th17 cell responses, ${ }^{56}$ suggesting that KLF4 may be involved in the development of a distinct SIRP $\alpha^{+} \mathrm{cDC}$ subset or regulate distinct functional modules in these cells.

Despite the clear role for SIRP $\alpha^{+}$cDC in intestinal Th17 cells homeostasis, some Th17 cells remain in the LP in all the models above. This may be because SIRP $\alpha^{+}$cDC are not completely depleted in these models, or that additional MNP subsets contribute to driving intestinal Th17 responses. Consistent with this latter possibility, Th17 responses to the intestinal commensal organism, segmented filamentous bacteria (SFB) require input from intestinal $m \phi .^{76}$

In addition to their role in Th17 homeostasis, IRF4dependent SIRP $\alpha^{+}$cDC are key for the development of Th2 responses. While studies on intestinal Th2 responses remain limited, Cd11c-cre.Irf $4^{\mathrm{fl} / \mathrm{fl}}$ mice do not develop a protective Th2 response to the parasitic worms Nippostrongylus brasiliensis $^{77}$ or Trichuris muris (J.U. Mayer, M. Demiri, W.W. Agace, A.S. MacDonald, M. Svensson-Frej, S.W. Milling, unpublished data). Further, in collaboration with the group of Dr. S. Milling (University of Glasgow), we recently identified 
a key role for migratory $\mathrm{CD} 03^{+} \mathrm{CD}_{11 \mathrm{~b}^{+}} \mathrm{cDC}$ in initiating Th2 responses in small intestinal-draining MLN in response to subserosal injection of Schistosoma mansoni eggs into the small intestine. In contrast, migratory $\mathrm{CD}_{103}{ }^{-} \mathrm{CD} 11 \mathrm{~b}^{+} \mathrm{cDC}$ drove Th2 responses in colonic draining MLN after subserosal egg injection into the colon (J.U. Mayer, M. Demiri, W.W. Agace, A.S.MacDonald, M.Svensson-Frej, S.W. Milling unpublished data). Thus the SIRP $\alpha^{+}$cDC subset responsible for driving Th2 immunity may depend on where in the intestine the infection takes place. Notably, Cd11c-cre.Klf4 ${ }^{\mathrm{t} / \mathrm{fl}}$ mice also have impaired Th2 responses, ${ }^{56}$ collectively suggesting that KLF4 expression in IRF4-dependent SIRP $\alpha^{+}$cDC is required for the development of Th2 immunity.

Finally, several reports have suggested a role for intestinal SIRP $\alpha^{+}$cDC in regulating innate lymphoid cell (ILC) function. Intestinal $\mathrm{CD}_{103}{ }^{+} \mathrm{CD}_{11} \mathrm{~b}^{+} \mathrm{cDC}$ produce IL-23 following challenge with flagellin or in response to Citrobacter rodentium (C.rodentium) infection, driving IL-22 expression by intestinal resident type 3 ILCs (ILC3). ${ }^{10,78}$ However CD103 ${ }^{-} \mathrm{CD} 11 \mathrm{~b}^{+}$ $\mathrm{cDC}$ and intestinal $\mathrm{m} \phi$ can also produce IL-23 and the relative importance of these MNP subsets as a source of IL-23 may depend on the model and the intestinal location under study. ${ }^{71,74,78-81}$

\section{Cooperation and antagonism between intestinal cDC subsets}

Although $\mathrm{XCR}^{+}$and SIRP $\alpha^{+}$cDC have non-redundant functions in intestinal immune homeostasis, there is also evidence of cooperation between these subsets. For example, while intestinal FoxP $3^{+} \mathrm{T}_{\text {reg }}$ are found in normal numbers in Cd11c-cre.Irf4 ${ }^{\mathrm{fl} / \mathrm{fl}}$ and huLangerin-DTA mice, ${ }^{54,71}$ mice lacking $\mathrm{XCR}^{+}{ }^{+} \mathrm{cDC}$ and $\mathrm{CD}_{103}{ }^{+} \mathrm{CD}_{11 \mathrm{~b}}{ }^{+} \mathrm{cDC}$ have decreased numbers of $\mathrm{T}_{\text {reg }}$ in the small intestine. ${ }^{71}$ Further, $\mathrm{iT}_{\text {reg }}$ generation in MLN in response to orally administered soluble protein antigen is reduced in Zbtb46-cre.Irf $8^{\mathrm{f} / \mathrm{fl}}$ mice that lack $\mathrm{XCR}^{+} \mathrm{cDC}$, while almost absent in diphtheria toxin-treated Zbtb46-DTR mice that lack all cDC; however, only Zbtb46DTR mice fail to develop oral tolerance. ${ }^{38} \mathrm{iT}_{\text {reg }}$ generation to commensal antigens is also dependent on $\mathrm{CDC}$ and here, $\mathrm{NOTCH} 2$-dependent SIRP $\alpha^{+} \mathrm{cDC}$ rather than XCR1 ${ }^{+} \mathrm{cDC}$ appear to play a dominant role. ${ }^{82}$ Finally while XCR $1^{+} \mathrm{cDC}$ are the superior cross-presenting antigen-presenting cell subset, there may also be redundancy in the induction of CTL responses in a setting of infection. Thus $\mathrm{CD} 8{ }^{+} \mathrm{T}$-cell responses to rotavirus are only partially reduced in $B a t f 3^{-1-}$ mice lacking XCR1 ${ }^{+}$cDC, but are completely ablated in Zbtb46-DTR mice depleted of all cDC. ${ }^{59}$

Two recent studies have also provided evidence of antagonism between intestinal XCR1 $1^{+}$and SIRP $\alpha^{+}$cDC. First, IL-12 production by $\mathrm{XCR} 1{ }^{+} \mathrm{cDC}$ appears to reduce the $\mathrm{Th} 2$ response to Heligmosomoides polygyrus infection ${ }^{61}$ and secondly, IL-23 production by $\mathrm{CX} 3 \mathrm{CR} 1^{+} \mathrm{CDC}$ and $\mathrm{m} \phi$ reduces IL- 12 production by XCR1 ${ }^{+} \mathrm{CDC}$ during C.rodentium infection, protecting mice from Th1 cell-mediated fatal immunopathology. ${ }^{74}$ These results suggest that $\mathrm{cDC}$ subsets can mutually dampen each other's responses, probably to help prevent excessive immune activation and to maintain a balanced immune response. A summary of the reported functions of intestinal XCR1 ${ }^{+}$and SIRP $\alpha^{+}$cDC can be seen in Figure 2 and Table 1.

\section{HUMAN CDC}

Three putative $\mathrm{CDC}$ subsets have been identified in the human small intestine that can be distinguished based on differential expression of CD141, CD103 and SIRP $\alpha$, together with a lack of the monocyte-macrophage markers CD64 and/or CD14. ${ }^{3,42,83}$ Comparative transcriptome profiling revealed close similarity between the two major human and murine cDC subsets; human small intestinal $\mathrm{CD} 103^{+} \mathrm{SIRP} \alpha^{-} \mathrm{cDC}$ resemble CD $141^{+} \mathrm{cDC}$ in other human tissues and murine intestinal $\mathrm{CD}_{103}{ }^{+}$ $\mathrm{CD}_{11 \mathrm{~b}}{ }^{-} \mathrm{cDC}$, while human small intestinal CD103 ${ }^{+}$SIRP $\alpha^{+}$ $\mathrm{cDC}$ resemble human blood-/tissue-derived $\mathrm{CD} 1 \mathrm{c}^{+} \mathrm{cDC}$ and murine $\mathrm{CD}_{103}{ }^{+} \mathrm{CD}_{11 \mathrm{~b}}{ }^{+} \mathrm{cDC}$. As in the mouse, $\mathrm{CD} 103^{-}$ $\mathrm{SIRP}^{+}$cells are also present in the human intestine, the majority of which express IRF4, CD11b and intermediate levels of CX3CR1. ${ }^{8,42}$ They are also heterogeneous for CCR2 expression, suggesting these may be equivalent to murine $\mathrm{CD}_{103}{ }^{-} \mathrm{CD} 11 \mathrm{~b}^{+} \mathrm{cDC}{ }^{8}$ Surprisingly, however, at the transcriptional level, these cells appeared to be more related to monocytes, ${ }^{42}$ indicating that they may represent a mixed population of cells due to insufficient gating criteria to exclude all monocyte-derived populations. Consistent with this possibility, Guilliams et al. recently provided evidence that CD14 ${ }^{-}$SIRP $\alpha^{\text {hi }}$ cells in human lung and intestine contain both $\mathrm{CD} 1 \mathrm{c}^{-} \mathrm{IRF}^{1 \mathrm{lo}} \mathrm{IRF}^{\mathrm{lo}}$ monocyte-derived cells, as well as bona fide $\mathrm{CD} 1 \mathrm{c}^{+} \mathrm{IRF} 4{ }^{\mathrm{hi}} \mathrm{cDC}^{84}$ Because of these findings we confine our discussion on the function of human intestinal cDC below to the $\mathrm{CD}_{103}{ }^{+} \mathrm{SIRP}^{+}$and $\mathrm{CD} 103^{+} \mathrm{SIRP} \alpha^{-}$cDC subsets.

As in mice, human intestinal $\mathrm{CD}_{103}{ }^{+} \mathrm{SIRP} \alpha^{+}$and $\mathrm{CD}_{103}{ }^{+} \mathrm{SIRP} \alpha^{-}$CDC express CCR7, indicating they have the potential to migrate to draining $\mathrm{LN}^{42,83}$ In line with this, $\mathrm{CD} 03^{+} \mathrm{CD}_{141}{ }^{+}$and $\mathrm{CD} 103^{+} \mathrm{CD} 1 \mathrm{c}^{+} \mathrm{cDC}$ can both be found within the migratory compartment of human MLN. ${ }^{85}$ The few studies that have assessed the in vitro functions of human intestinal cDC subsets thus far have highlighted both similarities and differences compared with their mouse homologs. As in mice, human small intestinal-derived cDC induce RA-dependent expression of $\alpha_{4} \beta_{7}$ and CCR9 on responding $\mathrm{T}$ cells and those from the small intestine imprint CCR9 expression on responding $\mathrm{T}$ cells more efficiently than colonic cDC. ${ }^{31,83}$ Human small intestinal $\mathrm{CD} 103{ }^{+} \mathrm{SIRP} \alpha^{+}$ CDC display higher aldehyde dehydrogenase activity and induce CCR9 on responding T-cells in vitro more efficiently than $\mathrm{CD}_{103}{ }^{+} \mathrm{SIRP} \alpha^{-} \mathrm{CDC}^{42}$ This former population also has the highest capacity to induce FoxP3 expression on $\mathrm{CD} 4{ }^{+} \mathrm{T}$ cells, whereas $\mathrm{CD} 103^{+} \mathrm{SIRP} \alpha^{-}$cDC appear more efficient at inducing Th1 differentiation. ${ }^{42}$ While the role of human cDC subsets in intestinal inflammation and infection remains to be determined, perturbations in the cDC compartment in inflamed mucosa and MLN have been observed in patients with Crohn's disease and ulcerative colitis. ${ }^{85}$ Altered aldehyde dehydrogenase activity in intestinal $\mathrm{cDC}$ has also been reported 
a

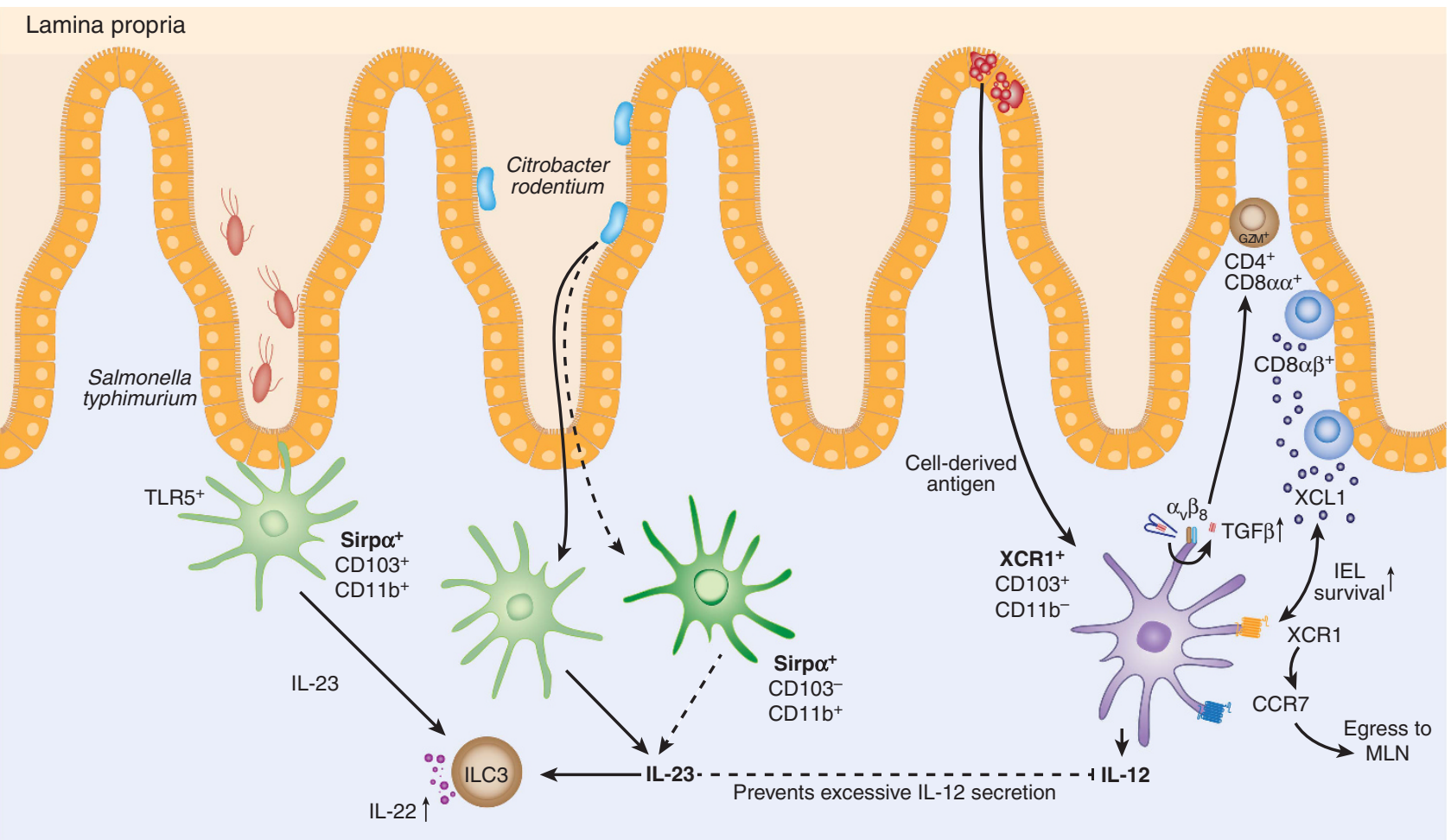

b

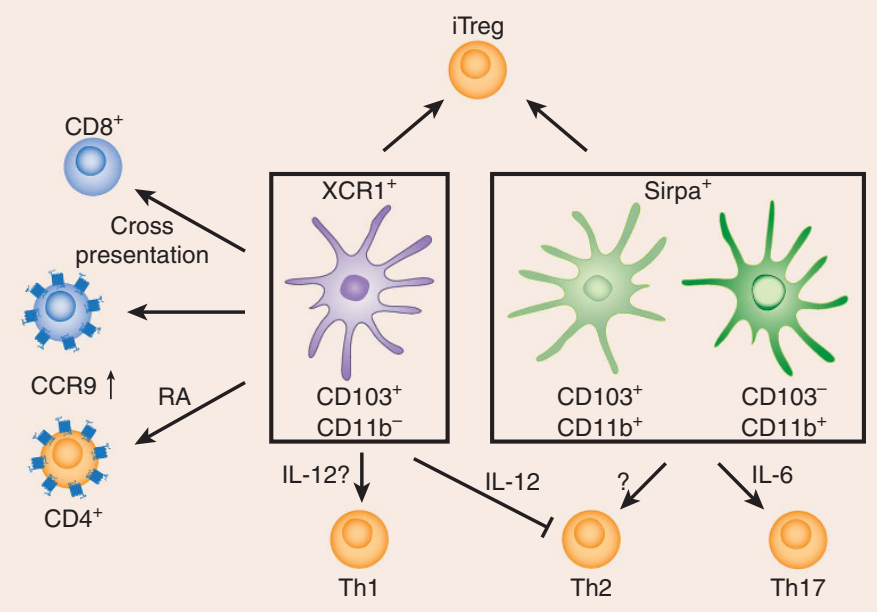

Figure 2 Functions of intestinal CDC. (a) cDC functions in the small intestinal LP. Sensing of flagellin via TLR5 or Citrobacter rodentium by $\mathrm{SIRP} \alpha^{+} \mathrm{CD} 103^{+} \mathrm{CD} 11 \mathrm{~b}^{+} \mathrm{CDC}$ and potentially SIRP $\alpha^{+} \mathrm{CD} 103^{-} \mathrm{CD} 11 \mathrm{~b}^{+} \mathrm{cDC}$ may induce IL-23 secretion, leading to ILC3 activation and IL-22 secretion. IL-23 production by SIRP $\alpha^{+} \mathrm{CDC}$ has also been described to limit IL-12 secretion by XCR $1^{+} \mathrm{CDC}$. XCR $1^{+} \mathrm{CDC}$ are the predominant APC that takes up cell-derived antigen for cross-presentation to $\mathrm{CD}^{+} \mathrm{T}$ cells. In addition they have been shown to promote the development of $\mathrm{CD} 8 \alpha \alpha^{+} \mathrm{CD} 4{ }^{+}$ cytotoxic IEL via the generation of active TGF $\beta$ through integrin $\alpha_{v} \beta_{8}$ and to sustain the survival of intestinal T cells via the XCR1/XCL1 axis. Finally XCL1 production by intestinal lymphocytes has been implicated in inducing CCR7 expression in XCR1 ${ }^{+} \mathrm{CDC}$, promoting their migration to MLN. (b) $\mathrm{cDC}$ functions in the intestinal lymph nodes. XCR1 ${ }^{+} \mathrm{CDC}$ are superior at inducing CD8 ${ }^{+} \mathrm{T}$-cell responses to cross-presented antigen and are the major $\mathrm{cDC}$ subset that produces RA, inducing CCR9 expression on responding CD4 ${ }^{+}$(orange cells) and CD8 ${ }^{+}$(blue cells) T cells. They also promote Th1 induction, but dampen the development of Th2 responses via release of IL-12. SIRP $\alpha^{+} \mathrm{cDC}$ are specialized in the induction of Th2 and Th17 responses. Both $\mathrm{XCR} 1^{+}$and SIRP $\alpha^{+} \mathrm{CDC}$ have been implicated in $\mathrm{iT}_{\text {reg }}$ conversion. Similar $\mathrm{DC}$ dependent processes are likely to occur in the colon and its draining lymph nodes, although many of these have not been explored directly in this tissue. APC, antigen-presenting cell; CDC, conventional dendritic cells; IEI, intraepithelial lymphocytes; LP, lamina propria; MLN, mesenteric lymph nodes; RA, retinoic acid; SIRP $\alpha$, signal regulatory protein $\alpha$; TFG $\beta$, transforming growth factor $\beta$; XCR1, X-C motif chemokine receptor 1.

in human IBD, although there is contradictory evidence about whether it is increased or reduced under these circumstances. ${ }^{85,86} \mathrm{~A}$ recent study identified a panel of lineage- specific markers suggested to identify XCR $1^{+} \mathrm{CDC}\left(\mathrm{CADM} 1^{\text {hi }}\right.$ SIRP $\alpha^{\text {lo }}$ CD $11 c^{\text {int }- \text { hi }}$ CD $26^{\text {hi }}$ IRF $^{\text {hi }}$ IRF $^{\text {lo }}$ ) and SIRP $\alpha^{+}$cDC $\left.\left(\mathrm{CADM}^{\mathrm{lo}} \mathrm{SIRP}^{\mathrm{hi}} \mathrm{CD} 1 \mathrm{c}^{\mathrm{hi}} \mathrm{CD} 11 \mathrm{c}^{\mathrm{hi}} \mathrm{IRF}^{\mathrm{hi}} \mathrm{IRF}^{\mathrm{lo}}\right)\right)$ across 
species and tissues that should prove useful in comparative phenotypic and functional studies between human and murine intestinal cDC subsets. ${ }^{84}$

\section{ENVIRONMENTAL CONDITIONING OF INTESTINAL CDC}

Intestinal $\mathrm{CDC}$ have many characteristics which set them apart from their counterparts in other tissues, indicating that their development and functional specializations may involve tissuespecific factors. The same cDC subsets also display distinct characteristics depending on their location within the intestine, probably reflecting the differences in anatomy, function, microbial composition and nature of micronutrients that are found along the length of the intestine. ${ }^{87}$

The presence of large numbers of $\mathrm{CD} 103^{+} \mathrm{CD} 11 \mathrm{~b}^{+} \mathrm{cDC}$ in the murine small intestine is perhaps the most obvious example of how the $\mathrm{CDC}$ lineages differ between the intestine and other tissues. As we have discussed, this appears to be at least partly due to tonic TGF $\beta$ signals, although the source and molecular basis of this effect are unclear (Montgomery et al., submitted for publication). Several dietary and bacterial metabolites have also been implicated in regulating intestinal cDC development and function. For example, RA has a major impact on the function of murine intestinal cDC, particularly in the small intestine. Tissue retinol levels are highest in the small intestine, due to uptake from the diet and potentially through delivery of liver-stored retinol via the bile, resulting in an increase in RA signaling in small intestinal $\mathrm{cDC}^{88-90}$ Such signaling induces aldehyde dehydrogenase 1a2 (Aldh1a2) expression in small intestinal $\mathrm{CDC}$ endowing them with the capacity to generate $\mathrm{CCR}^{+}{ }^{+} \alpha_{4} \beta_{7}^{+}$small intestinal homing T cells. ${ }^{30,31,91-92}$ Both epithelial cells and local stromal cells in the small intestinal LP have been implicated in the conversion of retinol to RA for delivery to local $\mathrm{cDC}^{89,93}$ Vitamin A deficient mice, or mice whose $\mathrm{CD} 11 \mathrm{c}^{+}$cells are unable to respond to RA, also display reduced numbers of intestinal $\mathrm{CD} 103{ }^{+} \mathrm{CD}_{11 \mathrm{~b}}{ }^{+} \mathrm{cDC}^{94}$. Intestinal $\mathrm{CD} 103^{+} \mathrm{CD} 11 \mathrm{~b}^{-} \mathrm{cDC}$ in these mice start to express langerin, ${ }^{94,95}$ indicating an additional role for RA in regulating intestinal cDC development. Consistent with this, RA has been proposed to promote the development of 'gut homing' pre-cDC in the $\mathrm{BM}^{96}$ and to participate in the imprinting of an 'intestine-like' phenotype on pre-cDC subsequent to their entry into the intestine. ${ }^{94,96}$ Additional metabolites implicated in modulating intestinal $\mathrm{CDC}$ function include AhR ligands and short chain fatty acids. For example mice lacking $\mathrm{AhR}$ on $\mathrm{CD} 11 \mathrm{c}^{+}$cells display minor alterations in intestinal cDC subset composition and their $\mathrm{CDC}$ display altered expression of Wnt signaling components, ${ }^{97}$ while butyrate signaling through the G-protein-coupled receptor GPR109A may impart an anti-inflammatory profile on colonic cDC, promoting their ability to generate $\mathrm{iT}_{\text {reg }}$ and IL-10 producing T cells. $^{98}$

\section{PART B. INTESTINAL MACROPHAGES}

Macrophages defined using the phenotypic and functional criteria discussed above are found throughout the gastrointestinal tract from before birth onwards. ${ }^{6,99,100}$ Most intestinal $\mathrm{m} \phi$ are found in the LP in close proximity to the epithelium and some may extend processes into the epithelial layer itself (see below). Discrete populations of $\mathrm{m} \phi$ are also present within the muscularis externa and serosa, where they engage in two-way interactions with the enteric nervous system, ${ }^{101-104}$ but here we will confine our discussion to the $\mathrm{m} \phi$ present in the intestinal mucosa. $\mathrm{M} \phi$ are relatively more abundant in the colon than small intestine, ${ }^{87}$ while those expressing high levels of $\mathrm{CD} 11 \mathrm{c}$ may be found closer to the epithelium than the CD11c ${ }^{-}$subset. ${ }^{105}$ A specific population expressing CD169 (sialoadhesin) is typically found near the crypt base, close to the submucosa and may have distinct functions and developmental requirements ${ }^{106,107}$ (and see below).

\section{Ontogeny of intestinal macrophages}

Like resident $m \phi$ in other tissues, mature $m \phi$ in the intestinal mucosa are large, vacuolated cells with abundant cytoplasm containing lysosomes and other granules. ${ }^{4}$ In mice they express classical $\mathrm{m} \phi$ markers including CD11b, CD64, MERTK and $\mathrm{F} 4 / 80$, but unlike $\mathrm{m} \phi$ in many other tissues, virtually all those in the intestine also express high levels of MHCII and CX3CR1. Most are also CD11c ${ }^{+}$(Table 2). ${ }^{4,108,109}$

Tissue-resident $\mathrm{m} \phi$ derive from a number of different precursors, including mesenchymal stem cells in the embryonic yolk sac (YS), fetal liver monocytes and adult BM-derived monocytes, with the relative contribution of each precursor source varying from organ to organ (see ref. 109 for review). Although embryonically derived $\mathrm{m} \phi$ are present in the mouse intestine at birth, BM-derived Ly6C hi ("classical") monocytes appear soon afterwards. Using a variety of approaches, we and others have shown that adult intestinal $\mathrm{m} \phi$ are entirely of haematopoietic origin and require constant replenishment by Ly6C $\mathrm{C}^{\text {hi }}$ monocytes. ${ }^{4,6,108}$ This process is dependent on CCR2, which is not only needed for emigration of Ly $6 \mathrm{C}^{\text {hi }}$ monocytes from the $\mathrm{BM}^{4,78,108,111}$ but also for their recruitment to the intestine. ${ }^{112}$ Thus while Ly6C $\mathrm{C}^{\text {hi }}$ monocytes were originally considered to be involved only in inflammatory processes, it is now clear that they can also give rise to tissue $m \phi$ under either steady state or inflammatory conditions. ${ }^{108}$

In contrast to these studies, it has been reported that a subpopulation of $\mathrm{CD} 11 \mathrm{c}^{-}$mature intestinal $\mathrm{m} \phi$ cannot be replenished by CCR2-dependent monocytes, although the exact origin of these $\mathrm{m} \phi$ was not examined directly. ${ }^{81,105}$ It has also been reported that intestinal $\mathrm{m} \phi$ may be dependent on CX3CR $1,{ }^{113,114}$ whose function is required for the survival of the alternative group of Ly6 $\mathrm{C}^{\mathrm{lo}}$ monocytes. ${ }^{115}$ However in our hands, this population of monocytes could not be found entering the intestine and $C \times 3 \mathrm{crl}^{-1-}$ mice had normal numbers of intestinal $\mathrm{m} \phi{ }^{108}$ The reasons for these discrepant results are unclear, but they could indicate that the relative contribution of different precursors to the intestinal $\mathrm{m} \phi$ pool may vary depending on factors in the environment, such as the nature of the microbiota. 
Table 2 Monocytes and $m \phi$ in the intestine

\begin{tabular}{|c|c|c|c|c|c|c|}
\hline \multicolumn{3}{|c|}{ Phenotype } & \multicolumn{3}{|c|}{ Ontogeny \& Differentiation } & \multirow{2}{*}{ Function } \\
\hline Common & & set Specific & GF & TF Involvement & Other Factors & \\
\hline \multirow{4}{*}{$\begin{array}{c}\text { CD11b+ }^{+} \\
\text {CD64 }^{+} \\
\text {F4/80 }^{+} \\
\text {MerTK }^{+} \\
\\
\text {Ly6G- }^{-} \\
\text {Siglec-F- } \\
\text { CD3-- }^{-} \\
\text {CD19- } \\
\text { B220- } \\
\text { NK1.1- }\end{array}$} & & $\begin{array}{l}\text { Ly6C hi } \\
\text { MHC IIneg } \\
\text { CD11C"neg } \\
\text { "P1" }\end{array}$ & \multirow{4}{*}{ 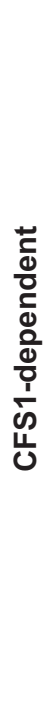 } & \multirow{4}{*}{$\begin{array}{c}\text { Runx } 3 \\
\text { PU.1 }\end{array}$} & \multirow{4}{*}{$\begin{array}{l}\text { TGF } \beta \text { R- } \\
\text { signalling } \\
\text { IL-10R- } \\
\text { signalling }\end{array}$} & \multirow{3}{*}{$\begin{array}{l}\text { - Functional plasticity } \\
\text { - Production of pro-inflammatory mediators in } \\
\text { response to TLR ligands etc }\end{array}$} \\
\hline & 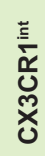 & $\begin{array}{l}\text { Ly6C hi-int } \\
\text { MHC II+ } \\
\text { CD11C }{ }^{+/-} \\
\text {"P2" }\end{array}$ & & & & \\
\hline & & $\begin{array}{l}\text { Ly6C neg } \\
\text { MHC II+ } \\
\text { CD11C }{ }^{+/-} \\
\text {"P3" }\end{array}$ & & & & \\
\hline & 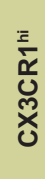 & $\begin{array}{l}\text { Ly6C neg } \\
\text { MHC II } \\
\text { CD11c } \\
\text { "P4"hi }\end{array}$ & & & & $\begin{array}{l}\text { - Scavenging, destruction of apoptotic cells, } \\
\text { microbes } \\
\text { - Tissue remodelling, epithelial renewal } \\
\text { - IL-10 production } \\
\text { - Local maintenance of } \mathrm{T}_{\text {reg }}\end{array}$ \\
\hline
\end{tabular}

Abbreviation: GF, growth factors; siLP, small intestinal lamina propria; TF, transcription factors.

Summary of the phenotypic markers, ontogeny and key functions of intestinal $\mathrm{mf}$ and their monocyte precursors. See main text for detail.

An important point to note here is that the embryonic $m \phi$ present at birth share many of the characteristic properties of their monocyte-derived counterparts in adult intestine including high-phagocytic activity, production of IL-10 and expression of scavenger receptors. ${ }^{116}$ Furthermore adult $\mathrm{CD} 11 \mathrm{c}^{+}$and $\mathrm{CD} 11 \mathrm{c}^{-} \mathrm{m} \phi$ differ by expression of only a few genes. ${ }^{105}$ These findings are consistent with the emerging view that location and not origin defines the functions of tissueresident $\mathrm{m} \phi .{ }^{110,117}$

After arrival in the mucosa, monocytes undergo a process of local differentiation through a series of phenotypic intermediaries known as the monocyte "waterfall" ${ }^{6,108}$ In mice this can be followed phenotypically, with $\mathrm{CX} 3 \mathrm{CR} 1{ }^{\text {int }} \mathrm{Ly}_{6} \mathrm{C}^{\text {hi }} \mathrm{MHCII}^{-}$ monocytes ("P1") first acquiring MHCII ("P2"), before losing Ly6C expression ("P3") and finally acquiring the CX3CR $1{ }^{\text {hi }} \mathrm{Ly}_{6 \mathrm{C}}{ }^{-} \mathrm{MHCII}{ }^{\mathrm{hi}}$ phenotype of mature resident $\mathrm{m} \phi$ ("P4"; Figure 1d). In mouse colon this differentiation process takes around 5-6 days from when the monocytes first enter, with the mature $m \phi$ having an estimated $t_{1 / 2}$ of 6-8 weeks. ${ }^{4,118}$ As with most resident tissue $\mathrm{m} \phi$, this developmental process in the intestine requires the CSF-1R. ${ }^{11}$

The properties of fully mature intestinal $\mathrm{m} \phi$ are acquired progressively as they develop through the local differentiation process described above (Table 2; Figure 3). Consistent with their morphological appearance, they express high levels of receptors associated with the recognition and uptake of apoptotic cells or opsonised organisms, including CD163 (heme/haptoglobin scavenger receptor), CD206 (mannose receptor), CD36, scavenger receptor $\mathrm{A}$, the receptor tyrosine kinases Axl and MerTK, the complement component
C1Q, T-cell immunoglobulin mucin protein 4 (TIM4) and $\alpha_{\mathrm{v}} \beta_{5}$ integrin (refs 107, 118, 119 and A.K. Kumawat \& A.McI. Mowat, unpublished data). In parallel they are avidly phagocytic and bactericidal even without additional stimulation., ${ }^{4119-122}$ Under steady state conditions they also produce mediators such as TNF $\alpha, \mathrm{IL}-1 \beta$ and IL- 10 , with up to $50 \%$ of mature intestinal $\mathrm{m} \phi$ producing IL-10 constitutively. ${ }^{108,118,123-125}$

Despite this evidence of being activated in situ, intestinal $\mathrm{m} \phi$ fail to respond to agents that normally activate $\mathrm{m} \phi$ by producing pro-inflammatory cytokines, nitric oxide (NO) or reactive oxygen intermediaries. This unresponsiveness is global in extent, as it also applies to non-Toll-like receptor (TLR) stimuli such as IFN $\gamma$ and NOD2 ligands, or when $\mathrm{m} \phi$ have taken up pathogens. ${ }^{108,122,126-129}$ These properties allow intestinal $\mathrm{m} \phi$ to act as efficient scavengers without generating the inflammation that normally ensues upon encounter of microbes and would compromise intestinal homeostasis.

A variety of factors in the local environment have been implicated in maintaining the anergy of intestinal $\mathrm{m} \phi$, including downregulation and/or active inhibition of TLR signaling pathways, despite normal expression of the TLRs ${ }^{122,130,131}$ and other pattern recognition receptors. ${ }^{108,122}$ Mice lacking IL-10 or its receptor develop microbiotadependent spontaneous IBD, associated with hyperactivity of intestinal $\mathrm{m} \phi^{105,123,132-135}$ and lack of signaling via the IL-10R on m $\phi$ leads to spontaneous colitis. ${ }^{123,135,136}$ Mutations in this pathway are associated with severe, early onset IBD in humans. ${ }^{137-139}$ IL-10 has many anti-inflammatory effects on myeloid cells, including epigenetic silencing of inflammatory gene loci via the activation of histone deacetylase. ${ }^{140,141}$ 
Whether the epigenome of resident intestinal $\mathrm{m} \phi$ shows evidence of this gene silencing remains to be determined.

TGF $\beta$ has been implicated in the TLR unresponsiveness of human intestinal $\mathrm{m} \phi,{ }^{142,143}$ but in our hands, mouse intestinal $\mathrm{m} \phi$ that lacked TGF $\beta \mathrm{R}$ signaling did not show enhanced responses to TLR ligation. ${ }^{144}$ Therefore there may be species differences in how intestinal $\mathrm{m} \phi$ reactivity is controlled. One possibility is that the IL-10 and TGF $\beta$ pathways play complementary roles and that these may vary with age. This is supported by findings that the effects of TGF $\beta$ can be observed from late in gestation onwards, ${ }^{142}$ while those of IL-10 appear to develop in a narrow time window in early neonatal

a

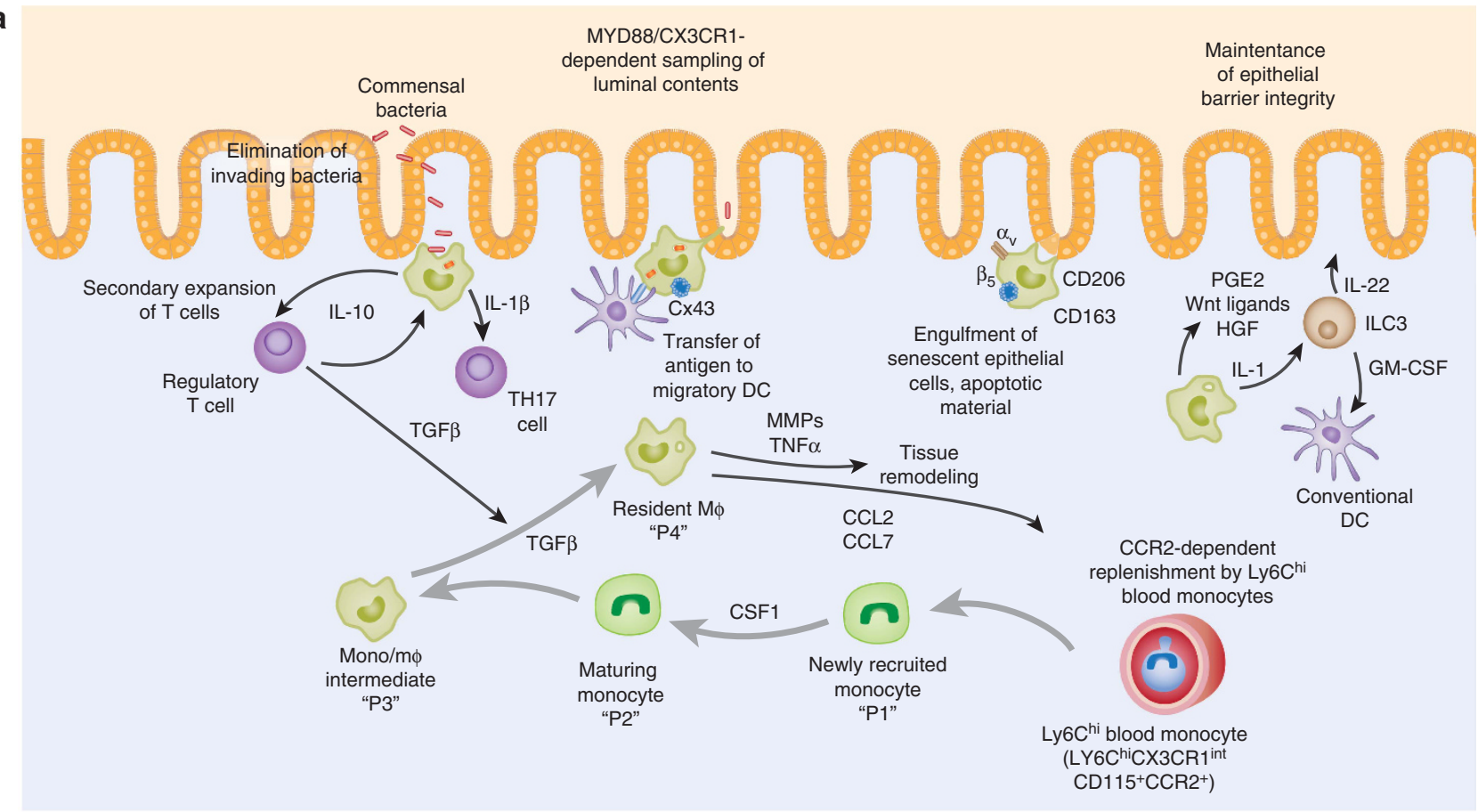

b

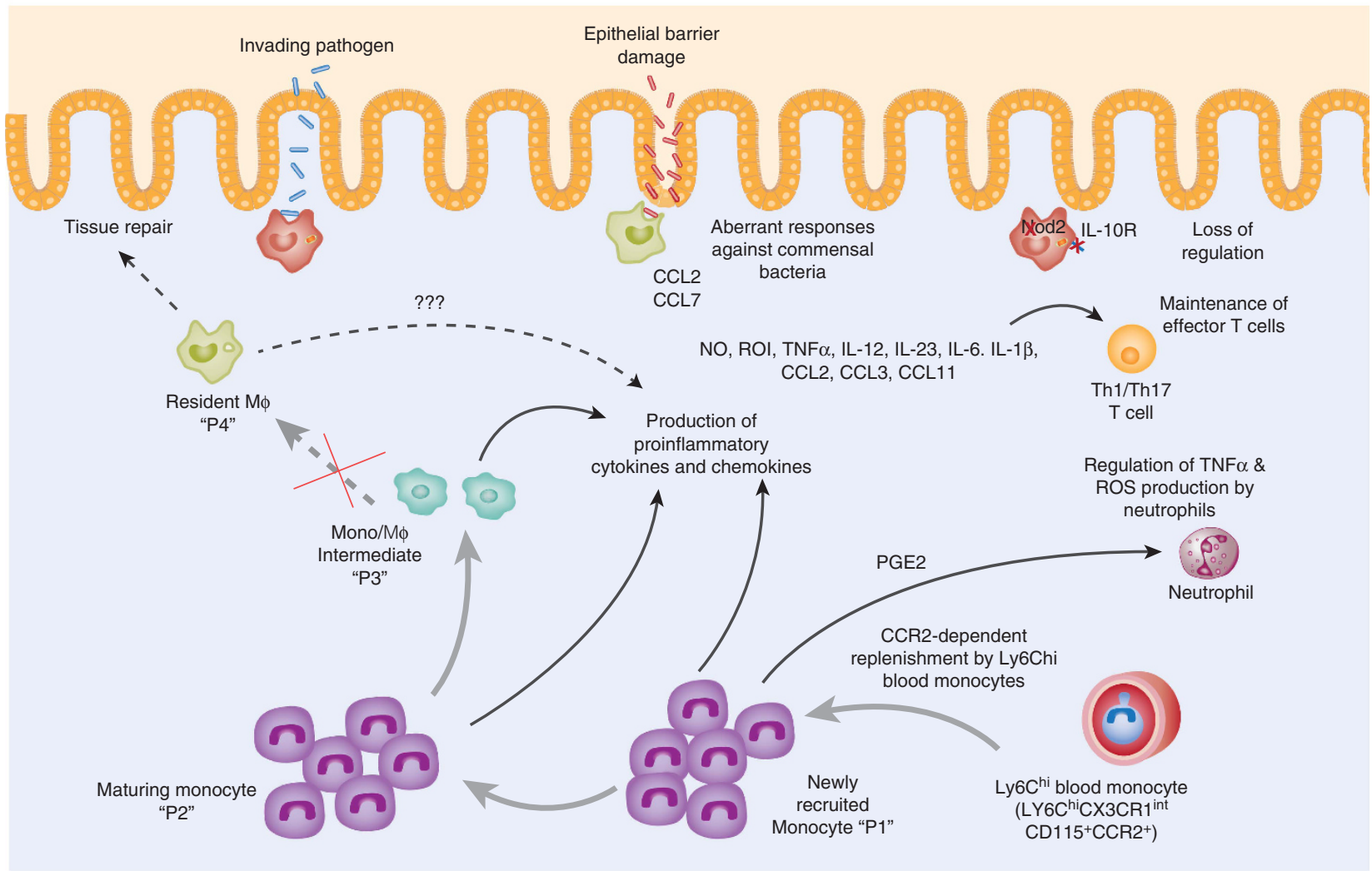


life. ${ }^{141}$ In parallel, IBD in $I L-10^{-/-}$mice can be prevented by exogenous replacement of the cytokine in neonatal, but not in adult animals, consistent with there being a limited period during which IL-10 can cause epigenetic silencing of $\mathrm{m} \phi$ genes. ${ }^{141}$

Finally, resident intestinal $\mathrm{m} \phi$ express a variety of inhibitory receptors with the potential for restricting their activation in a cell intrinsic manner, such as CD200R, SIRP $\alpha$ and Axl. Intestinal $\mathrm{m} \phi$ from mice lacking Axl show evidence of an increased inflammatory profile, ${ }^{145}$ but there are contradictory findings on whether absence of CD200-CD200 receptor signaling pathway leads to $\mathrm{m} \phi$ activation or inflammation in the intestine. ${ }^{146,147}$ In contrast to what is observed with intestinal cDC (see above), mice with a mutant form of SIRP $\alpha$ that lacks the signaling domain do not have alterations in the intestinal monocyte/m $\phi$ compartment in steady state intestine and are also not susceptible to inflammation (ref. 72) and C.L. Scott \& A.McI. Mowat, unpublished data).

Perhaps surprisingly, intestinal $\mathrm{m} \phi$ retain their global hyporesponsiveness to TLR stimulation even when the microbiota is entirely lacking in germ free and embryonic mice (refs 115,139) and our unpublished observations).

\section{PHYSIOLOGICAL FUNCTIONS OF INTESTINAL MACROPHAGES}

\section{Symbiosis with the microbiota}

As mucosal $\mathrm{m} \phi$ are typically found in close proximity to the epithelium and are more abundant in colon compared with small intestine, it seems reasonable to assume that one of their main roles in vivo is the uptake and clearance of microbes that have crossed the epithelial barrier (Figure 3). Indeed bacteria have been detected within lamina propria $\mathrm{m} \phi$ from steady state intestine $^{100}$ and CX3CR1 ${ }^{+} \mathrm{m} \phi$ account for most of the uptake of organisms when Escheria coli are administered orally. ${ }^{148}$ In this regard CX3CR1 ${ }^{+}$phagocytes have been observed to send processes from the LP across the epithelium to capture luminal bacteria in a CX3CL1-dependent manner and although originally thought to be $\mathrm{CDC},{ }^{149}$ it now seems likely that these were $m \phi .{ }^{109}$ As noted above, intestinal $\mathrm{m} \phi$ are actively bactericidal, possibly reflecting the constitutive expression of mediators such as TNF $\alpha$ and metallothionein-dependent $\mathrm{Zn}^{2+}$ cations. ${ }^{150}$ Recent work also suggests that CCR2-dependent $\mathrm{m} \phi$ may be required for the induction of Th17 cell responses to segmented filamentous bacteria in steady state intestine. ${ }^{76}$ Because these functions are achieved without causing inflammation, $\mathrm{m} \phi$ are one component of the host response that ensures a healthy symbiotic relationship with the commensal microbiota.

\section{Maintenance of epithelial homeostasis}

The presence of $m \phi$ in the intestine from before birth and in germ free mice indicates they are likely to have physiological functions in addition to scavenging bacteria. The intestinal epithelium is one of the most dynamic and rapidly dividing tissues in the body and this constant movement and cell loss requires continuous remodeling of the underlying extracellular matrix, as well as disposal of effete cells. The high phagocytic activity of intestinal $\mathrm{m} \phi$ is ideally suited to these processes and indeed, cytokeratin ${ }^{+}$inclusions have been observed within $\mathrm{m} \phi$ from steady state intestine (Figure 3). ${ }^{121,144}$ Resting intestinal $\mathrm{m} \phi$ also express a variety of mediators that can promote tissue remodeling such as metalloproteinases and TNF $\alpha$ (Figure 3). ${ }^{151,152}$

That these functions of intestinal $\mathrm{m} \phi$ are necessary to maintain epithelial integrity is suggested by studies showing increased epithelial susceptibility to inflammatory insults in animals lacking $\mathrm{m} \phi$ themselves or with loss of TLR or AhR signaling on myeloid cells. ${ }^{97,153-155}$ Furthermore, loss of $\mathrm{m} \phi$ in Csf1 $1^{-1-}$ mice or following depletion with anti-CSF-1R antibody was found to result in dysregulated enterocyte differentiation and loss of Paneth cells. ${ }^{156,157}$ A similar phenotype has been reported in mice lacking $\mathrm{AhR}$ expression on $\mathrm{CD}_{11 \mathrm{c}^{+}}$cells. However these experiments did not define whether the effects reflected a property of $\mathrm{cDC}$, $\mathrm{m} \phi$ or both. ${ }^{97}$ In this respect, $\mathrm{m} \phi$ have been reported to produce several mediators, that could drive intestinal epithelial cell renewal and differentiation, including prostaglandin

Figure 3 Intestinal $\mathrm{m} \phi$ in health and inflammation. (a) In steady state adult intestine, Ly6C $\mathrm{C}^{\text {hi }}$ monocytes are recruited continuously from the bloodstream in a CCR2-dependent manner. After arrival in the mucosa, they develop through the "monocyte waterfall", in which $\mathrm{LyC}^{\text {hi }} \mathrm{MHCll}^{-} \mathrm{CX} 3 \mathrm{CR} 1^{{ }^{\text {int }}} \mathrm{F} 4 / 80^{\mathrm{lo}}$ monocytes ("P1") acquire MHCII ("P2"), before losing Ly6C to become Ly6C ${ }^{-} \mathrm{MHCII}^{+} \mathrm{F} 4 / 80^{+}$monocyte/macrophage intermediaries ("P3") and finally acquiring high levels of CX3CR1 as they terminally differentiate into the majority population of resident macrophages ("P4"). This process is determined by factors specific to the intestinal microenvironment, with the final step being at least partly dependent on TGF $\beta$. The resident macrophages engage in important homeostatic functions, as they have avid phagocytic activity, express scavenger receptors, metalloproteases, and produce cytokines and chemokines. As a result, the macrophages can clear effete tissue cells and bacteria that cross the epithelium, contribute to tissue remodeling, recruit further monocytes and interact with local immune cells such as T cells and ILC. They also send processes through the epithelium to capture luminal antigens and can transfer antigen to neighboring migratory CDC via Connexin 43 (Cx43). All these activities take place without inflammation occurring, due to IL-10 from T cells and macrophages preventing activation and also because of intrinsic mechanisms that inhibit PRR signaling in macrophages. $\mathrm{IL}-10$ produced by resident macrophages also drives secondary expansion and survival of FoxP3 ${ }^{+} \mathrm{T}_{\text {reg }}$ that have been primed in lymph nodes. (b) Mucosal inflammation can be caused by invasive pathogens, damage to the epithelial barrier leading to increased exposure to commensal bacteria, or to defects in macrophage control pathways such as NOD2 or IL-10 function. Under these circumstances, there is enhanced recruitment of Ly6C ${ }^{\text {hi }}$ monocytes and the normal differentiation process is disrupted, allowing accumulation of pro-inflammatory monocytes and early intermediary macrophages. These release inflammatory mediators such as NO, ROI, TNF $\alpha$, IL-12, IL-23, IL- 6 and IL-1 $\beta$ which cause tissue damage, as well as activating other inflammatory cells including Th1 or Th17 effector cells. Pre-existing resident macrophages may contribute to these inflammatory events, or may remain poised to initiate tissue repair when required. Monocytes can also help limit pathology by releasing $\mathrm{PGE}_{2}$, which inhibits the harmful effects of neutrophils. $\mathrm{NO}$, nitric oxide; $\mathrm{PGE}_{2}$, prostaglandin $\mathrm{E}_{2}$; $\mathrm{ROI}$, reactive oxygen intermediaries. 
$\mathrm{E}_{2} \quad\left(\mathrm{PGE}_{2}\right)$, hepatocyte growth factor and Wnt signaling ligands. ${ }^{97,158-160}$

\section{Maintenance of immunological homeostasis in the mucosa} The numbers of endogenous FoxP3 ${ }^{+} \mathrm{T}$ cells are higher in the colon than small intestine, correlating with the relative abundance of $\mathrm{m} \phi$ in each site and mucosal $\mathrm{m} \phi$ have been found to stimulate the differentiation of $\mathrm{T}_{\text {reg }}$ in vitro. ${ }^{48} \mathrm{In}$ part, this may reflect their constitutive production of IL-10 and indeed, the fact that a higher proportion of $\mathrm{m} \phi$ produces IL-10 in the colon than in small intestine is consistent with the relative abundance of $\mathrm{T}_{\text {reg }}$ at these sites. ${ }^{123}$ Intestinal $\mathrm{m} \phi$-derived IL-10 has also been implicated in the local expansion of antigenspecific $\mathrm{iT}_{\text {reg }}$ that have been primed in MLN by orally administered protein. In parallel, impaired IL-10 production by $\mathrm{m} \phi$ in $C \times 3 \mathrm{crl}^{-1-}$ mice results in a failure to induce oral tolerance. $^{39}$ In the context of inflammation, IL-10 from intestinal $\mathrm{CD} 11 \mathrm{~b}^{+}$cells considered to be $\mathrm{m} \phi$, has been shown to stabilize the function of $\mathrm{iT}_{\text {reg }}$ by maintaining the expression of FoxP3. ${ }^{124}$ TRAF6 expression in CD11c ${ }^{+}$MNPs has also been implicated in the generation of $\mathrm{iT}_{\text {reg }}$ in vitro and mice lacking this pathway develop spontaneous Th2 cell-mediated intestinal inflammation, ${ }^{34}$ although it remains to be proven whether the relevant $\mathrm{CD} 11 \mathrm{c}^{+}$cells are $\mathrm{m} \phi$ or $\mathrm{cDC}$ in this case. Despite these findings, IL-10 production from $\mathrm{m} \phi$ themselves appears not to be essential for preventing spontaneous IBD in response to the microbiota. ${ }^{135,161}$ Thus although prevention of $\mathrm{m} \phi$ activation via IL-10R signaling is crucial for preventing inflammatory reactions to the microbiota, cells such as $\mathrm{CD} 4^{+} \mathrm{T}$ cells may be more important sources of the IL-10.

Intestinal $\mathrm{m} \phi$ may also be involved in the survival and/or maintenance of other immune cells in the mucosa. For instance, IL-1 produced by LP $\mathrm{m} \phi$ in response to the microbiota has been reported to drive the production of granulocyte macrophage CSF (GM-CSF) from ILC3, which in turn promotes intestinal cDC development. ${ }^{162} \mathrm{IL}-1 \beta$ produced by intestinal $\mathrm{m} \phi$ in response to the microbiota can also sustain the expansion and survival of IL-17-producing Th17 cells in the mucosa. ${ }^{125}$

Mature intestinal $\mathrm{m} \phi$ also produce monocyte-specific chemokines such as CCL2, CCL7, CCL11 and CXCL16, as well as chemokines that can recruit other immune cells. ${ }^{112,163}$ Thus resident $\mathrm{m} \phi$ may also regulate their own replenishment and maintain a dynamic status quo.

\section{Macrophages and induction of adaptive immune responses} Intestinal $\mathrm{m} \phi$ are poor professional antigen-presenting cells in vitro and do not express CCR7 or migrate in afferent lymph to $M L N,{ }^{2,13,109}$ indicating they are unlikely to play a major role in the initiation of adaptive immune responses. However, evidence from other systems suggests that antigen-specific $\mathrm{T}$ cells require a second stimulus from an antigen-presenting cell in non-lymphoid tissues to acquire full effector functions. ${ }^{164}$ Although $\mathrm{MHCII}^{+} \mathrm{m} \phi$ would be well placed to serve this function in the mucosa, a role of this kind remains to be assessed.
One way in which $\mathrm{m} \phi$ might contribute indirectly to the priming of mucosal immunity comes from evidence that orally administered proteins or bacteria taken up by CX3CR ${ }^{\text {hi }} \mathrm{m} \phi$ in LP can be passed to migratory CD103 ${ }^{+}$cDC. ${ }^{148,165}$ In the case of protein antigen, this transfer process has been suggested to involve Connexin 43 (Cx43)- mediated gap junctions formed between $\mathrm{m} \phi$ and $\mathrm{cDC}$ and this leads to the induction of oral tolerance. ${ }^{165}$ Division of labor amongst intestinal $\mathrm{m} \phi$ and $\mathrm{CD}_{103}{ }^{+} \mathrm{cDC}$ of this kind has also been suggested to be involved in the induction of local Th17 responses to segmented filamentous bacteria. ${ }^{76}$

\section{Macrophages in intestinal inflammation}

Disorders such as IBD and infection are accompanied by infiltration with $\mathrm{m} \phi$ and monocytes. ${ }^{4}$ Our own and other work indicates that Ly6 $\mathrm{C}^{\text {hi }}$ monocytes entering the intestine fail to differentiate fully to become mature $\mathrm{m} \phi$ in the presence of inflammation, failing to upregulate IL-10 or to become unresponsive to stimulation. ${ }^{6,105,108}$ In addition, there is enhanced recruitment of monocytes above the baseline levels seen in steady state intestine and as a result, the early stages of the monocyte waterfall $\left(\mathrm{CX} 3 \mathrm{CR} 1^{\text {int }} \mathrm{Ly}_{6} \mathrm{C}^{\text {hi }} \mathrm{MHCII}^{+/-}\right)$dominate the inflammatory infiltrate. ${ }^{166}$ Although predominantly dependent on the CCL2-CCR2 axis, ${ }^{81,127,163,167-169}$ other chemokine receptors can also come into play in inflammation, including CCR1 and its ligand CCL3 ${ }^{170}$ Contradictory findings have been reported on whether the CX3CR1 chemokine receptor plays a role in recruiting inflammatory $\mathrm{m} \phi$ in experimental IBD, with both increased and decreased susceptibility having been observed in $\mathrm{C} x 3 \mathrm{cr} 1^{-1-}$ mice. ${ }^{114,171,172}$

It is not known why monocytes that arrive in the inflamed mucosa do not go through the full differentiation process seen in normal intestine. One possibility is that they simply do not survive long enough to be able to progress through the entire waterfall, which normally takes up to a week to complete. ${ }^{108}$ Alternatively there may be loss of the factors that usually drive $\mathrm{m} \phi$ survival and development in the healthy mucosa. Interestingly, the fate of monocytes may also be determined before they arrive in the mucosa, as reported in mice with intestinal toxoplasmosis, where IL-12 produced by local cDC induces NK cells in the BM to produce IFN $\gamma$, leading to altered differentiation of monocytes or their precursors. ${ }^{18}$

Monocytes and immature $\mathrm{m} \phi$ are the main producers of proinflammatory mediators such as IL-1, IL-6, TNF $\alpha$, IL-23, NO and reactive oxygen intermediates that are found in inflamed intestine. ${ }^{6,81,105,118,120,135,146,154,167,169,170,174-178}$ As well as contributing to tissue damage directly, these mediators can also recruit and activate additional immune effector cells. IL-23 from monocyte-derived cells is critical for protective Th17 in infections by bacteria such as C.rodentium or Helicobacter hepaticus $^{74,174}$ and together with IL-1 $\beta$ it induces the production of antimicrobial and cyto-protective IL-22 by stimulating ILC $3{ }^{74,81}$ Inflammatory monocytes can also promote IFN $\gamma$ and IL-17-producing Th1 and Th17 cells via the production of IL-12 and IL-6, respectively. ${ }^{133,177}$ As in the steady state, these effects on $\mathrm{T}$ cells are likely to involve a role in local maintenance 
of previously primed effector $\mathrm{T}$ cells, rather than in initiation of the immune response. Pro-inflammatory monocytes $/ \mathrm{m} \phi$ also produce chemokines such as CCL2, CCL3, CCL4, CCL5, CCL8 and CCL11, which recruit monocytes, eosinophils and neutrophils. ${ }^{106,167,178}$

It is not clear if pre-existing resident $\mathrm{m} \phi$ can also contribute to these inflammatory processes. The resident $\mathrm{m} \phi$ population does not expand markedly in chemically induced or T-celldependent colitis and there is little or no change in function or gene expression under these conditions. ${ }^{6,108,120}$ Indeed IL-10 secretion by intestinal $m \phi$ is important in limiting IL-23mediated pathology during experimental infection with C.rodentium. ${ }^{123}$ Nevertheless, resident $\mathrm{m} \phi$ can produce pro-inflammatory mediators when colitis develops in the absence of IL-10 signaling, ${ }^{135,174}$ perhaps reflecting retained functional plasticity when IL-10 driven epigenetic silencing is lacking. ${ }^{141}$ It is also possible that there is heterogeneity amongst resident $\mathrm{m} \phi$ in their ability to respond to inflammatory stimuli. Indeed the small subset of $\mathrm{CD} 169^{+}$mucosal $\mathrm{m} \phi$ expands during inflammation and recruits neutrophils via the production of CCL8. ${ }^{106}$

\section{Intestinal macrophages and Th2-mediated immune responses}

$\mathrm{M} \phi$ are also important in the Th2 driven immune responses involved in resistance to infection by intestinal helminths, when there is infiltration by monocytes and expansion of the local $\mathrm{m} \phi$ population. ${ }^{179-183}$ Under these conditions, production of IL-4 and IL-13, together with activation of peroxisome proliferatoractivated receptor $\gamma$ (PPAR $\gamma$ ) by cyclooxygenase-2 (COX2), generates genuine alternatively activated $\mathrm{m} \phi$, with release of typical mediators such as arginase and resistin-like molecule $\alpha$ $($ RELM- $\alpha) .{ }^{180,182,184,185}$ Depletion of monocytes or mature $\mathrm{m} \phi$ inhibits the expulsion of helminths, ${ }^{179,186-188}$ which may be because $m \phi$ and their products can attack the parasites directly. Alternatively activated $m \phi$ of this kind also help generate a hostile environment by promoting smooth muscle contractility, depriving metabolites such as glucose $e^{187,188}$ and by producing chemokines that recruit additional anti-parasite effector cells such as eosinophils. ${ }^{169,178}$

In contrast to what has been described in the pleural or peritoneal cavities, ${ }^{189,190}$ IL-4- and CSF-1-driven proliferation of resident $\mathrm{m} \phi$ does not seem to occur to any significant extent during intestinal helminth infection. Under these conditions, most $\mathrm{m} \phi$ are derived from Ly6 $\mathrm{C}^{\mathrm{hi}}$ monocytes and only low amounts of local proliferation can be observed. ${ }^{182}$

\section{Monocytes and macrophages and resolution of intestinal inflammation}

$\mathrm{M} \phi$ play central roles in tissue repair and restoration of homeostasis in intestinal inflammation, as depletion of $\mathrm{m} \phi$ delays recovery from experimental colitis. ${ }^{153,155,191}$ A variety of mechanisms have been implicated in the repair function of intestinal $\mathrm{m} \phi$, including TLR/MyD88-dependent restoration of the epithelial stem cell niche via stimulation of $\mathrm{PGE}_{2}$ production from stromal cells. ${ }^{155,192}$ Recovery from Heligmosomoides polygyrus induced intestinal pathology also involves $\mathrm{m} \phi$ producing chemokine ligands for CXCR2 on fibroblasts, driven in part via CD64. ${ }^{193}$ The ability of $\mathrm{m} \phi$ to induce IL-22 production by ILC3 also favours restitution of a damaged epithelial barrier, ${ }^{81,194}$ while TGF $\beta R$-mediated suppression of IL-33 production by $\mathrm{m} \phi$ has been proposed to mediate resolution of chemical colitis. ${ }^{191}$ Arginase produced by alternatively activated $m \phi$ in parasite infections is a further important tissue repair mechanism under these conditions. ${ }^{195,196}$ Although generally thought of as a pro-inflammatory mediator, IL-1 $\beta$ production by myeloid cells has also been shown to promote epithelial repair after acute colitis, ${ }^{197}$ while IL-36 produced by both $\mathrm{m} \phi$ and epithelial cells may contribute to enhanced turnover of enterocytes as a reparative response to inflammation. ${ }^{198}$

As many of the properties of resident $\mathrm{m} \phi$ in the healthy intestine would be ideally suited to help in tissue repair, cells of this kind that have survived the initial inflammatory insult may be important in this process. Alternatively, some recruited monocytes may differentiate into more mature $\mathrm{m} \phi$ with repair functions, as has been described for monocytes infiltrating the damaged heart and after depletion of liver Kupffer cells. ${ }^{199,200}$ Inflammatory monocytes themselves have been shown to inhibit the pathological effects of neutrophils during the intestinal inflammation induced by dextran sodium sulfate or Toxoplasma gondii. ${ }^{155,175}$ In the latter case, this reflected synthesis of $\mathrm{PGE}_{2}$ by monocytes ${ }^{175}$ and other work has confirmed enhanced $\mathrm{PGE}_{2}$ production by monocytes during colitis. ${ }^{135}$ Production of GM-CSF and VEGF-C during inflammation may reprogramme the differentiation of monocytes into $\mathrm{m} \phi$ that produce reparative mediators such as arginase, prostaglandins and IL-13. ${ }^{201,202}$ Thus the overall role of the monocyte- $\mathrm{m} \phi$ lineage in intestinal inflammation may reflect a balance between local pathogenic and regulatory mechanisms.

\section{HUMAN INTESTINAL MACROPHAGES}

$M \phi$ show a similar distribution along the human gastrointestinal tract and they share the morphological features of their mouse counterparts, as well as being refractory to stimulation and expressing MHCII and phagocytic receptors. ${ }^{86,108,119,203-206}$ However, many phenotypic markers of the myeloid lineage including CD11b, F4/80 and CD11c are not conserved between the species and a variety of different markers need to be used to distinguish human intestinal $\mathrm{m} \phi$ from cDC, including CD14, CD33, CD64 and CD68. ${ }^{5} \mathrm{CD} 163$ or CD206 are also expressed by most mature $m \phi$ in humans, but they express low amounts of CD14, which is found at high levels on classical monocytes and immature $\mathrm{m} \phi{ }^{86,108,119,203-206}$

Using markers of this kind, it can be shown that a monocyte$\mathrm{m} \phi$ "waterfall" exists in the normal human intestine, with some $\mathrm{CD} 14^{\mathrm{hi}}$ monocytes being present, together with intermediary stages and a major population of $\mathrm{CD} 14^{\mathrm{lo}} \mathrm{CD} 163^{+} \mathrm{CD} 206^{+}$ $\mathrm{m} \phi{ }^{5,108}$ Interestingly, recent studies in human BM transplantation have suggested that as in mice, human intestinal $\mathrm{m} \phi$ are continuously replenished by circulating precursors (Dr M. Haniffa, University of Newcastle, Personal Communication). 
Nevertheless, there may be some differences between $\mathrm{m} \phi$ in steady state human and mouse intestine. Thus human intestinal $\mathrm{m} \phi$ are capable of producing RA via expression of the Aldh1a1 gene whereas in mice, RA production appears limited to cDC. ${ }^{85,86}$ Furthermore, as we have noted earlier, TGF $\beta$ may play a more important role in the hyporesponsiveness of human intestinal $m \phi$ to TLR stimulation than it does in mice. ${ }^{143}$ Indeed, there appear to be several differences in how responsiveness to pattern recognition receptors is regulated in human and murine $\mathrm{m} \phi$ in general. ${ }^{207}$ As in mice however, IL10 plays an essential role in controlling the pro-inflammatory potential of human intestinal $\mathrm{m} \phi$ and non-functional mutations in the IL-10R lead to severe, early onset IBD. ${ }^{137-139}$ The mucosa in Crohn's disease also shows evidence of open chromatin in the pro-inflammatory gene loci normally silenced by IL-10. ${ }^{141}$

As in mice, studies of human inflammatory bowel disease have highlighted the presence of large numbers of classical $\left(\mathrm{CD} 14^{\mathrm{hi}}\right)$ monocytes and a relatively decreased frequency of mature $\mathrm{m} \phi .{ }^{85,86,108,176,208-210}$ Furthermore, these immature cells are responsible for producing large amounts of the proinflammatory mediators that typify these disorders, including TNF $\alpha$, IL-1, IL-18, IL-23, NO and reactive oxygen intermediates. ${ }^{129,203,204,208,211-212}$ Production of RA by infiltrating monocytes and $\mathrm{m} \phi$ may also be enhanced during IBD, perhaps secondary to increased levels of GM-CSF. ${ }^{86}$ Interestingly, autocrine signaling via the RA receptor has been suggested to contribute to the production of TNF $\alpha$ by $m \phi .^{86}$

\section{ENVIRONMENTAL CONDITIONING OF INTESTINAL MONOCYTES AND MACROPHAGES}

As with $\mathrm{cDC}$, the characteristics of intestinal $\mathrm{m} \phi$ set them apart from their counterparts in other tissues and reveal a role for the local environment in imprinting their properties. Thus we have found that although $\mathrm{m} \phi$ in the dermis and intestine are both derived from classical monocytes, ${ }^{116,213}$ these cells show transcriptional differences very soon after arriving in the two tissues, becoming increasingly distinct as they develop into mature $m \phi .^{144}$ TGF $\beta$ again may play a central role in the terminal differentiation of monocytes into intestinal m $\phi$. TGF $\beta$ is known to upregulate CX3CR1 on other $m \phi^{214}$ and mice lacking KLF10, a transcription factor involved in the TGF $\beta R$ pathway, have reduced numbers of intestinal CX3CR $1^{\text {hi }} \mathrm{m} \phi .^{215}$ TGF $\beta$ does not seem to be required for the initial stages of monocyte recruitment and maturation, consistent with the findings from other tissues that a number of different factors need to act in concert to specify resident $\mathrm{m} \phi$ differentiation. ${ }^{216}$ Active epigenetic marking of the enhancer of the Runt-related transcription factor 3 (Runx-3) was also recently shown to be a selective feature of resident intestinal $m \phi^{217}$ and Runx-3 is known to interact with TGF $\beta$ signaling in other cells including Langerhans cells. ${ }^{218}$ However, its role in intestinal $\mathrm{m} \phi$ development has not been explored directly. RA is required for the development of the $\mathrm{CD} 169^{+}$subset of intestinal $\mathrm{m} \phi$, but not of other intestinal $\mathrm{m} \phi^{94,107,219}$ and dietary amino acids such as glutamine have also been proposed to be important for $\mathrm{m} \phi$ development in the small intestine. ${ }^{220}$

A number of mechanisms may help drive the production of IL-10 by intestinal $\mathrm{m} \phi$, including products of the microbiota such as the short chain fatty acid butyrate ${ }^{98,221}$ or ligands for the MyD88 signaling pathway, ${ }^{105,134,140,222}$ as well as for the $\mathrm{AhR}^{97}$ and PPAR receptor pathways. ${ }^{223,224}$ Intestinal $\mathrm{m} \phi$ in $C \times 3 \mathrm{cr} 1^{-1-}$ mice show defective IL-10 production $^{39}$ and fractalkine (CX3CL1), the only ligand for CX3CR1 downregulates nuclear factor- $\kappa \mathrm{B}$ and pro-inflammatory cytokine production in BM-derived $m \phi$ via PPAR $\gamma$ signaling. ${ }^{25}$ Thus there could be links between these pathways in the regulatory functions of intestinal $\mathrm{m} \phi$. IL-10 itself can also drive some of the properties of intestinal $\mathrm{m} \phi$ in addition to their hyporesponsiveness to stimulation, including the expression of scavenger receptors such as CD163. ${ }^{123,134}$

Finally, although there is much reduced recruitment of monocytes to the colon of germ free mice compared with conventionally housed controls, ${ }^{116}$ mature $\mathrm{m} \phi$ remain present in germ free colon, indicating the microbiota does not play an essential role in their development. However, the production of IL- $1 \beta$ by intestinal $m \phi$ is dependent on the presence of the microbiota $^{125,162}$ and exposure to the microbiota can also act as a feedback mechanism by limiting the generation of active IL- $1 \beta$ from pro-IL- $1 \beta .^{226}$ Whether there are additional effects on $\mathrm{m} \phi$ differentiation and function remains to be determined.

\section{SUMMARY}

The normal intestinal mucosa contains large populations of $\mathrm{cDC}$ and $\mathrm{m} \phi$ which play distinct, but complementary roles in local immune responses and tissue homeostasis. Whereas cDC are specialised in sampling the microenvironment, carrying antigens to the draining $\mathrm{LN}$ and shaping the nature and location of subsequent $\mathrm{T}$-cell responses, $\mathrm{m} \phi$ are sessile scavengers that clear microbes and contribute to tissue remodeling, as well as helping to maintain an anti-inflammatory milieu in the mucosa. Both populations have properties that make them distinct from their counterparts in other tissues, reflecting adaptation to the special demands and characteristics of the intestine. As well as containing a unique subset of IRF4dependent SIRP $\alpha^{+}$DC that expresses both CD103 and CD11b, cDC from the small intestine have an enhanced ability to produce RA and promote the generation of guthoming $\mathrm{T}$ cells. Intestinal SIRP $\alpha^{+} \mathrm{cDC}$ have been associated with the generation of mucosal Th17 and Th2 responses, while $\mathrm{XCR}^{+}{ }^{+} \mathrm{cDC}$ are involved in the induction of Th1 immunity, cross-priming of $\mathrm{CD}^{+}{ }^{+} \mathrm{T}$ cells, generation of gut tropic $\mathrm{T}$ cells and establishment/maintenance of the intestinal intra-epithelial lymphocyte compartment. In contrast both $\mathrm{cDC}$ branches appear to contribute to mucosal $\mathrm{iT}_{\text {reg }}$ induction. Whether these functions are hard-wired or vary depending on context remains to be fully explored.

Unlike resident $\mathrm{m} \phi$ in many other tissues, those in the intestine require constant replenishment from circulating classical monocytes that differentiate locally after their arrival in the mucosa, under tissue-specific control. This allows 
constant surveillance of the intestine and the opportunity to react rapidly and flexibly to changes in its environment. Under inflammatory conditions, the local differentiation process that normally generates mature, anti-inflammatory $\mathrm{m} \phi$ from the same monocyte precursors is dysregulated, allowing accumulation of pro-inflammatory cells with pathological functions.

Understanding more about the factors that determine the tissue-specific properties of intestinal $\mathrm{cDC}$ and $\mathrm{m} \phi$ and how these cells change in response to inflammation or infection will be important challenges for the future.

\section{AUTHORS CONTRIBUTIONS}

All authors have contributed equally to the writing and editing of this review.

\section{DISCLOSURE}

The authors declared no conflict of interest.

c) 2017 Society for Mucosal Immunology

\section{REFERENCES}

1. Bekiaris, V., Persson, E.K. \& Agace, W.W. Intestinal dendritic cells in the regulation of mucosal immunity. Immunol. Rev. 260, 86-101 (2014).

2. Cerovic, V., Bain, C.C., Mowat, A.M. \& Milling, S.W. Intestinal macrophages and dendritic cells: what's the difference? Trends Immunol. 35, 270-277 (2014).

3. Persson, E.K., Scott, C.L., Mowat, A.M. \& Agace, W.W. Dendritic cell subsets in the intestinal lamina propria: ontogeny and function. Eur. J. Immunol. 43, 3098-3107 (2013).

4. Bain, C.C. \& Mowat, A.M. Macrophages in intestinal homeostasis and inflammation. Immunol. Rev. 260, 102-117 (2014).

5. Scott, C.L., Wright, P.B., Milling, S.W. \& Mowat, A.M. Isolation and identification of conventional dendritic cell subsets from the intestine of mice and men. Methods Mol. Biol. 1423, 101-118 (2016).

6. Tamoutounour, S. et al. CD64 distinguishes macrophages from dendritic cells in the gut and reveals the Th1-inducing role of mesenteric lymph node macrophages during colitis. Eur. J. Immunol. 42, 3150-3166 (2012).

7. Luda, K.M. et al. IRF8 transcription-factor-dependent classical dendritic cells are essential for intestinal T cell homeostasis. Immunity 44, 860-874 (2016).

8. Scott, C.L. et al. CCR2CD103 intestinal dendritic cells develop from DCcommitted precursors and induce interleukin-17 production by $\mathrm{T}$ cells. Mucosal Immunol. 8, 327-339 (2014).

9. Guilliams, M. et al. Dendritic cells, monocytes and macrophages: a unified nomenclature based on ontogeny. Nat. Rev. Immunol. 14, 571-578 (2014).

10. Satpathy, A.T. et al. Notch2-dependent classical dendritic cells orchestrate intestinal immunity to attaching-and-effacing bacterial pathogens. Nat. Immunol. 14, 937-948 (2013).

11. Ryan, G.R. et al. Rescue of the colony-stimulating factor 1 (CSF-1)nullizygous mouse (Csf1(op)/Csf1(op)) phenotype with a CSF-1 transgene and identification of sites of local CSF-1 synthesis. Blood $98,74-84$ (2001).

12. Bogunovic, M. et al. Origin of the lamina propria dendritic cell network. Immunity 31, 513-525 (2009).

13. Cerovic, V. et al. Intestinal CD103(-) dendritic cells migrate in lymph and prime effector T cells. Mucosal Immunol. 6, 104-113 (2012).

14. Cerovic, V. et al. Lymph-borne CD8alpha + dendritic cells are uniquely able to cross-prime CD8 + T cells with antigen acquired from intestinal epithelial cells. Mucosal Immunol. 8, 38-48 (2015).

15. Diehl, G.E. et al. Microbiota restricts trafficking of bacteria to mesenteric lymph nodes by CX(3)CR1(hi) cells. Nature 494, 116-120 (2013).

16. Huang, F.P. et al. A discrete subpopulation of dendritic cells transports apoptotic intestinal epithelial cells to T cell areas of lymph nodes. J. Exp. Med. 191, 435-444 (2000).
17. Jang, M.H. et al. CCR7 is critically important for migration of dendritic cells in intestinal lamina propria to mesenteric lymph nodes. J. Immunol. 176, 803-810 (2006).

18. Worbs, T. et al. Oral tolerance originates in the intestinal immune system and relies on antigen carriage by dendritic cells. J. Exp. Med. 203, 519527 (2006).

19. Farache, J. et al. Luminal bacteria recruit CD103 + dendritic cells into the intestinal epithelium to sample bacterial antigens for presentation. Immunity 38, 581-595 (2013).

20. Knoop, K.A., McDonald, K.G., McCrate, S., McDole, J.R. \& Newberry, R.D. Microbial sensing by goblet cells controls immune surveillance of luminal antigens in the colon. Mucosal Immunol. 8, 198-210 (2015).

21. McDole, J.R. et al. Goblet cells deliver luminal antigen to CD103+ dendritic cells in the small intestine. Nature 483, 345-349 (2012).

22. Jang, M.H. et al. Intestinal villous $M$ cells: an antigen entry site in the mucosal epithelium. Proc. Natl Acad. Sci. USA 101, 6110-6115 (2004).

23. Mazzini, E., Massimiliano, L., Penna, G. \& Rescigno, M. Oral tolerance can be established via gap junction transfer of fed antigens from CX3CR1 + macrophages to CD103 + dendritic cells. Immunity 40, 248-261 (2014).

24. Knoop, K.A., Miller, M.J. \& Newberry, R.D. Transepithelial antigen delivery in the small intestine: different paths, different outcomes. Curr. Opin. Gastroenterol. 29, 112-118 (2013).

25. Johansson-Lindbom, B. et al. Functional specialization of gut CD103+ dendritic cells in the regulation of tissue-selective T cell homing. J. Exp. Med. 202, 1063-1073 (2005).

26. Macpherson, A.J. \& Uhr, T. Induction of protective IgA by intestinal dendritic cells carrying commensal bacteria. Science 303, 1662-1665 (2004).

27. Johansson-Lindbom, B., Svensson, M., Wurbel, M.A., Malissen, B., Marquez, G. \& Agace, W. Selective generation of gut tropic T cells in gutassociated lymphoid tissue (GALT): requirement for GALT dendritic cells and adjuvant. J. Exp. Med. 198, 963-969 (2003).

28. Svensson, M. et al. CCL25 mediates the localization of recently activated CD8alphabeta $(+)$ lymphocytes to the small-intestinal mucosa. J. Clin. Invest. 110, 1113-1121 (2002).

29. Hammerschmidt, S.I. et al. Retinoic acid induces homing of protective T and $\mathrm{B}$ cells to the gut after subcutaneous immunization in mice. J. Clin. Invest. 121, 3051-3061 (2011).

30. Iwata, M., Hirakiyama, A., Eshima, Y., Kagechika, H., Kato, C. \& Song, S.Y. Retinoic acid imprints gut-homing specificity on Tcells. Immunity 21, 527-538 (2004).

31. Jaensson, E. et al. Small intestinal CD103 + dendritic cells display unique functional properties that are conserved between mice and humans. J. Exp. Med. 205, 2139-2149 (2008).

32. Huang, G., Wang, Y. \& Chi, H. Control of Tcell fates and immune tolerance by p38alpha signaling in mucosal CD103+ dendritic cells. J. Immunol. 191, 650-659 (2013).

33. Ramalingam, R. et al. Dendritic cell-specific disruption of TGF-beta receptor II leads to altered regulatory T cell phenotype and spontaneous multiorgan autoimmunity. J. Immunol. 189, 2139-3893 (2012).

34. Han, D. et al. Dendritic cell expression of the signaling molecule TRAF6 is critical for gut microbiota-dependent immune tolerance. Immunity $\mathbf{3 8}$, 1211-1222 (2013).

35. Manicassamy, S. et al. Activation of beta-catenin in dendritic cells regulates immunity versus tolerance in the intestine. Science 329 , 849-853 (2010).

36. Hammer, G.E. et al. Expression of A20 by dendritic cells preserves immune homeostasis and prevents colitis and spondyloarthritis. Nat. Immunol. 12, 1184-1193 (2011).

37. Liang, J. et al. Inflammatory Th1 and Th17 in the intestine are each driven by functionally specialized dendritic cells with distinct requirements for MyD88. Cell Rep. 17, 1330-1343 (2016).

38. Esterhazy, D., Loschko, J., London, M., Jove, V., Oliveira, T.Y. \& Mucida, D. Classical dendritic cells are required for dietary antigen-mediated induction of peripheral T cells and tolerance. Nat. Immunol. 17, 545-555 (2016).

39. Hadis, U. et al. Intestinal tolerance requires gut homing and expansion of FoxP3(+ ) regulatory T cells in the lamina propria. Immunity 34, 237-246 (2011). 
40. Loschko, J. et al. Absence of MHC class II on cDCs results in microbial-dependent intestinal inflammation. J. Exp. Med. 213, 517534 (2016).

41. Gurka, S., Hartung, E., Becker, M. \& Kroczek, R.A. Mouse conventional dendritic cells can be universally classified based on the mutually exclusive expression of XCR1 and SIRPalpha. Front. Immunol. 6, 35 (2015).

42. Watchmaker, P.B. et al. Comparative transcriptional and functional profiling defines conserved programs of intestinal DC differentiation in humans and mice. Nat. Immunol. 15, 98-108 (2014).

43. Kinnebrew, M.A. \& Pamer, E.G. Innate immune signaling in defense against intestinal microbes. Immunol. Rev. 245, 113-131 (2012).

44. Fujimoto, K. et al. A new subset of CD103 + CD8alpha + dendritic cells in the small intestine expresses TLR3, TLR7, and TLR9 and induces Th1 response and CTL activity. J. Immunol. 186, 6287-6295 (2011).

45. Muzaki, A.R. et al. Intestinal CD103(+)CD11b(-) dendritic cells restrain colitis via IFN-gamma-induced anti-inflammatory response in epithelial cells. Mucosal Immunol. 9, 336-351 (2016).

46. Flores-Langarica, A. et al. Systemic flagellin immunization stimulates mucosal CD103 + dendritic cells and drives Foxp3 + regulatory T cell and IgA responses in the mesenteric lymph node. J. Immunol. 189, 57455754 (2012).

47. Yrlid, U., Cerovic, V., Milling, S., Jenkins, C.D., Klavinskis, L.S. \& MacPherson, G.G. A distinct subset of intestinal dendritic cells responds selectively to oral TLR7/8 stimulation. Eur. J. Immunol. 36, 2639-2648 (2006).

48. Denning, T.L. et al. Functional specializations of intestinal dendritic cell and macrophage subsets that control Th17 and regulatory T cell responses are dependent on the T cell/APC ratio, source of mouse strain, and regional localization. J. Immunol. 187, 733-747 (2011).

49. Houston, S.A., Cerovic, V., Thomson, C., Brewer, J., Mowat, A.M. \& Milling, S. The lymph nodes draining the small intestine and colon are anatomically separate and immunologically distinct. Mucosal Immunol. 9, 468-478 (2016).

50. Becker, M. et al. Ontogenic, phenotypic, and functional characterization of XCR1 $(+)$ dendritic cells leads to a consistent classification of intestinal dendritic cells based on the expression of XCR1 and SIRPalpha. Front. Immunol. 5, 326 (2014).

51. Sichien, D.B.N., Lambrecht, M. \& Guilliams, C.L. Scott. Development of conventional dendritic cells: from common bone marrow progenitors to multiple subsets in peripheral tissues. Mucosal Immunol.; advance online publication, 15 February 2017; doi: 10.1038/mi.2017.8 (2017).

52. Edelson, B.T. et al. Peripheral CD103 + dendritic cells form a unified subset developmentally related to CD8alpha + conventional dendritic cells. J. Exp. Med. 207, 823-836 (2010).

53. Ginhoux, F. et al. The origin and development of nonlymphoid tissue CD103 + DCs. J. Exp. Med. 206, 3115-3130 (2009).

54. Persson, E.K. et al. IRF4 transcription-factor-dependent CD103(+) $\mathrm{CD} 11 \mathrm{~b}(+)$ dendritic cells drive mucosal T helper 17 cell differentiation. Immunity 38, 958-969 (2013).

55. Lewis, K.L. et al. Notch2 receptor signaling controls functional differentiation of dendritic cells in the spleen and intestine. Immunity 35,780 791 (2011).

56. Tussiwand, R. et al. Klf4 expression in conventional dendritic cells is required for T helper 2 cell responses. Immunity 42, 916-928 (2015).

57. Scott, C.L. et al. The transcription factor Zeb2 regulates development of conventional and plasmacytoid DCs by repressing Id2. J. Exp. Med. 213, 897-911 (2016).

58. Ohta, T. et al. Crucial roles of XCR1-expressing dendritic cells and the XCR1-XCL1 chemokine axis in intestinal immune homeostasis. Sci. Rep. 6, 23505 (2016).

59. Sun, T., Rojas, O.L., Li, C., Ward, L.A., Philpott, D.J. \& Gommerman, J.L. Intestinal Batf3-dependent dendritic cells are required for optimal antiviral T-cell responses in adult and neonatal mice. Mucosal Immunol.; advance online publication, 7 September 2016; doi: 10.1038/mi.2016.79 (2016).

60. Chudnovskiy, A. et al. Host-protozoan interactions protect from mucosal infections through activation of the inflammasome. Cell 167, 444456.e414 (2016).
61. Everts, B. et al. Migratory CD103 + dendritic cells suppress helminthdriven type 2 immunity through constitutive expression of IL-12. J. Exp. Med. 213, 35-51 (2016).

62. Koyama, M. et al. Donor colonic CD103 + dendritic cells determine the severity of acute graft-versus-host disease. J. Exp. Med. 212, 1303-1321 (2015).

63. Mashayekhi, M. et al. CD8alpha(+) dendritic cells are the critical source of interleukin-12 that controls acute infection by Toxoplasma gondii tachyzoites. Immunity 35, 249-259 (2011).

64. Cortez, V.S. et al. CRTAM controls residency of gut CD4+CD8 + T cells in the steady state and maintenance of gut CD $4+$ Th17 during parasitic infection. J. Exp. Med. 211, 623-633 (2014).

65. Mucida, D. et al. Transcriptional reprogramming of mature CD4(+) helper Tcells generates distinct MHC class II-restricted cytotoxic T lymphocytes. Nat. Immunol. 14, 281-289 (2013).

66. Reis, B.S., Rogoz, A., Costa-Pinto, F.A., Taniuchi, I. \& Mucida, D. Mutual expression of the transcription factors Run $\times 3$ and ThPOK regulates intestinal CD4(+) T cell immunity. Nat. Immunol. 14, 271-280 (2013).

67. Travis, M.A. \& Sheppard, D. TGF-beta activation and function in immunity. Annu. Rev. Immunol. 32, 51-82 (2014).

68. Yokota, A. et al. GM-CSF and IL-4 synergistically trigger dendritic cells to acquire retinoic acid-producing capacity. Int. Immunol. 21, 361-377 (2009).

69. Boucard-Jourdin, M. et al. beta8 integrin expression and activation of TGF-beta by intestinal dendritic cells are determined by both tissue microenvironment and cell lineage. J. Immunol. 197, 1968-1978 (2016).

70. Veenbergen, S. et al. Colonic tolerance develops in the iliac lymph nodes and can be established independent of CD103 dendritic cells. Mucosal Immunol. 9, 894-906 (2015).

71. Welty, N.E., Staley, C., Ghilardi, N., Sadowsky, M.J., Igyarto, B.Z. \& Kaplan, D.H. Intestinal lamina propria dendritic cells maintain $T$ cell homeostasis but do not affect commensalism. J. Exp. Med. 210, 2011-2024 (2013).

72. Schlitzer, A. et al. IRF4 transcription factor-dependent CD11b + dendritic cells in human and mouse control mucosal IL-17 cytokine responses. Immunity 38, 970-983 (2013).

73. Scott, C.L., Tfp, Z.M., Beckham, K.S., Douce, G. \& Mowat, A.M. Signal regulatory protein alpha (SIRPalpha) regulates the homeostasis of CD103(+) CD11b(+) DCs in the intestinal lamina propria. Eur. J. Immunol. 44, 3658-3668 (2014).

74. Aychek, T. et al. IL-23-mediated mononuclear phagocyte crosstalk protects mice from Citrobacter rodentium-induced colon immunopathology. Nat. Commun. 6, 6525 (2015).

75. Wenzel, U.A., Jonstrand, C., Hansson, G.C. \& Wick, M.J. CD103+ CD11b + dendritic cells induce Th17 T cells in Muc2-deficient mice with extensively spread colitis. PLOS ONE 10, e0130750 (2015).

76. Panea, C. et al. Intestinal monocyte-derived macrophages control commensal-specific Th17 responses. Cell Rep. 12, 1314-1324 (2015).

77. Gao, Y. et al. Control of T helper 2 responses by transcription factor IRF4dependent dendritic cells. Immunity 39, 722-732 (2013).

78. Kinnebrew, M.A. et al. Interleukin 23 production by intestinal CD103(+) $\mathrm{CD} 11 \mathrm{~b}(+)$ dendritic cells in response to bacterial flagellin enhances mucosal innate immune defense. Immunity 36, 276-287 (2012).

79. Longman, R.S. et al. CX(3)CR1 $(+)$ mononuclear phagocytes support colitis-associated innate lymphoid cell production of IL-22. J. Exp. Med. 211, 1571-1583 (2014).

80. Manta, C. et al. CX(3)CR1 (+) macrophages support IL-22 production by innate lymphoid cells during infection with Citrobacter rodentium. Mucosal Immunol. 6, 177-188 (2012).

81. Seo, S.U. et al. Intestinal macrophages arising from CCR2 $(+)$ monocytes control pathogen infection by activating innate lymphoid cells. Nat. Commun. 6, 8010 (2015).

82. Nutsch, K. et al. Rapid and efficient generation of regulatory $T$ cells to commensal antigens in the periphery. Cell Rep. 17, 206-220 (2016).

83. Mann, E.R. et al. Compartment-specific immunity in the human gut: properties and functions of dendritic cells in the colon versus the ileum. Gut 65, 256-270 (2016).

84. Guilliams, M. et al. Unsupervised high-dimensional analysis aligns dendritic cells across tissues and species. Immunity 45, 669-684 (2016). 
85. Magnusson, M.K. et al. Macrophage and dendritic cell subsets in IBD: $\mathrm{ALDH}+$ cells are reduced in colon tissue of patients with ulcerative colitis regardless of inflammation. Mucosal Immunol. 9, 171-182 (2016).

86. Sanders, T.J. et al. Increased production of retinoic acid by intestinal macrophages contributes to their inflammatory phenotype in patients with Crohn's disease. Gastroenterology 146, 1278-1288 e1271-1272 (2014).

87. Mowat, A.M. \& Agace, W.W. Regional specialization within the intestinal immune system. Nat. Rev. Immunol. 14, 667-685 (2014).

88. Jaensson-Gyllenback, E. et al. Bile retinoids imprint intestinal CD103+ dendritic cells with the ability to generate gut-tropic T cells. Mucosal Immunol. 4, 438-447 (2011).

89. McDonald, K.G. et al. Epithelial expression of the cytosolic retinoid chaperone cellular retinol binding protein II is essential for in vivo imprinting of local gut dendritic cells by lumenal retinoids. Am. J. Pathol. 180, 984997 (2012).

90. Villablanca, E.J. et al. MyD88 and retinoic acid signaling pathways interact to modulate gastrointestinal activities of dendritic cells. Gastroenterology 141, 176-185 (2011).

91. Agace, W.W. \& Persson, E.K. How vitamin A metabolizing dendritic cells are generated in the gut mucosa. Trends Immunol. 33, 42-48 (2012).

92. Molenaar, R. et al. Expression of retinaldehyde dehydrogenase enzymes in mucosal dendritic cells and gut-draining lymph node stromal cells is controlled by dietary vitamin A. J. Immunol. 186, 1934-1942 (2011).

93. Vicente-Suarez, I. et al. Unique lamina propria stromal cells imprint the functional phenotype of mucosal dendritic cells. Mucosal Immunol. 8, 141-151 (2015).

94. Zeng, R., Bscheider, M., Lahl, K., Lee, M. \& Butcher, E.C. Generation and transcriptional programming of intestinal dendritic cells: essential role of retinoic acid. Mucosal Immunol. 9, 183-193 (2016).

95. Chang, S.Y. et al. Lack of retinoic acid leads to increased langerinexpressing dendritic cells in gut-associated lymphoid tissues. Gastroenterology 138, 1468-1478. 1478.e1461-1466 (2010).

96. Zeng, R. et al. Retinoic acid regulates the development of a gut-homing precursor for intestinal dendritic cells. Mucosal Immunol. 6, 847-856 (2013).

97. Chng, S.H. et al. Ablating the aryl hydrocarbon receptor (AhR) in CD11C + cells perturbs intestinal epithelium development and intestinal immunity. Sci. Rep. 6, 23820 (2016).

98. Singh, N. et al. Activation of Gpr109a, receptor for niacin and the commensal metabolite butyrate, suppresses colonic inflammation and carcinogenesis. Immunity 40, 128-139 (2014).

99. Bain, C.C. etal. Resident and pro-inflammatory macrophages in the colon represent alternative context-dependent fates of the same Ly6C(hi) monocyte precursors. Mucosal Immunol. 6, 498-510 (2013).

100. Hume, D.A., Perry, V.H. \& Gordon, S. The mononuclear phagocyte system of the mouse defined by immunohistochemical localisation of antigen F4/80: macrophages associated with epithelia. Anat. Rec. 210, 503-512 (1984).

101. Boeckxstaens, G.E. \& de Jonge, W.J. Neuroimmune mechanisms in postoperative ileus. Gut 58, 1300-1311 (2009).

102. Gabanyi, I., Muller, P.A., Feighery, L., Oliveira, T.Y., Costa-Pinto, F.A. \& Mucida, D. Neuro-immune Interactions Drive Tissue Programming in Intestinal Macrophages. Cell 164, 378-391 (2016).

103. Muller, P.A. etal. Crosstalk between muscularis macrophages and enteric neurons regulates gastrointestinal motility. Cell 158, 300-313 (2014).

104. Veiga-Fernandes, H. \& Mucida, D. Neuro-Immune Interactions at Barrier Surfaces. Cell 165, 801-811 (2016).

105. Rivollier, A., He, J., Kole, A., Valatas, V. \& Kelsall, B.L. Inflammation switches the differentiation program of Ly6Chi monocytes from antiinflammatory macrophages to inflammatory dendritic cells in the colon. J. Exp. Med. 209, 139-155 (2012).

106. Asano, K. et al. Intestinal CD169(+) macrophages initiate mucosal inflammation by secreting CCL8 that recruits inflammatory monocytes. Nat. Commun. 6, 7802 (2015).

107. Hiemstra, I.H. et al. The identification and developmental requirements of colonic CD169(+) macrophages. Immunology 142, 269-278 (2014).

108. Bain, C.C. et al. Resident and pro-inflammatory macrophages in the colon represent alternative context-dependent fates of the same Ly6Chi monocyte precursors. Mucosal Immunol. 6, 498-510 (2013).
109. Schulz, O. et al. Intestinal CD103+, but not CX3CR1+, antigen sampling cells migrate in lymph and serve classical dendritic cell functions. J. Exp. Med. 206, 3101-3114 (2009).

110. Ginhoux, F. \& Guilliams, M. Tissue-resident macrophage ontogeny and homeostasis. Immunity 44, 439-449 (2016).

111. Serbina, N.V. \& Pamer, E.G. Monocyte emigration from bone marrow during bacterial infection requires signals mediated by chemokine receptor CCR2. Nat. Immunol. 7, 311-317 (2006).

112. Takada, Y. et al. Monocyte chemoattractant protein-1 contributes to gut homeostasis and intestinal inflammation by composition of IL-10producing regulatory macrophage subset. J. Immunol. 184, 26712676 (2010).

113. Hochheiser, K. et al. Exclusive CX3CR1 dependence of kidney DCs impacts glomerulonephritis progression. J. Clin. Invest. 123, 4242-4254 (2013).

114. Medina-Contreras, O. et al. CX3CR1 regulates intestinal macrophage homeostasis, bacterial translocation, and colitogenic Th17 responses in mice. J. Clin. Invest. 121, 4787-4795 (2011).

115. Landsman, L. et al. CX3CR1 is required for monocyte homeostasis and atherogenesis by promoting cell survival. Blood 113, 963-972 (2009).

116. Bain, C.C. et al. Constant replenishment from circulating monocytes maintains the macrophage pool in the intestine of adult mice. Nat. Immunol. 15, 929-937 (2014).

117. Amit, I., Winter, D.R. \& Jung, S. The role of the local environment and epigenetics in shaping macrophage identity and their effect on tissue homeostasis. Nat. Immunol. 17, 18-25 (2016).

118. Zigmond, E. \& Jung, S. Intestinal macrophages: well educated exceptions from the rule. Trends Immunol. 34, 162-168 (2013).

119. Smith, P.D., Smythies, L.E., Shen, R., Greenwell-Wild, T., Gliozzi, M. \& Wahl, S.M. Intestinal macrophages and response to microbial encroachment. Mucosal Immunol. 4, 31-42 (2011).

120. Weber, B., Saurer, L., Schenk, M., Dickgreber, N. \& Mueller, C. CX3CR1 defines functionally distinct intestinal mononuclear phagocyte subsets which maintain their respective functions during homeostatic and inflammatory conditions. Eur. J. Immunol. 41, 773-779 (2011).

121. Nagashima, R., Maeda, K., Imai, Y. \& Takahashi, T. Lamina propria macrophages in the human gastrointestinal mucosa: their distribution, immunohistological phenotype, and function. J. Histochem. Cytochem. 44, 721-731 (1996).

122. Smythies, L.E. et al. Human intestinal macrophages display profound inflammatory anergy despite avid phagocytic and bacteriocidal activity. J. Clin. Invest. 115, 66-75 (2005).

123. Krause, P. et al. IL-10-producing intestinal macrophages prevent excessive antibacterial innate immunity by limiting IL-23 synthesis. Nat. Commun. 6, 7055 (2015).

124. Murai, M. et al. Interleukin 10 acts on regulatory $T$ cells to maintain expression of the transcription factor Foxp3 and suppressive function in mice with colitis. Nat. Immunol. 10, 1178-1184 (2009).

125. Shaw, M.H., Kamada, N., Kim, Y.G. \& Nunez, G. Microbiota-induced IL1 beta, but not IL-6, is critical for the development of steady-state TH17 cells in the intestine. J. Exp. Med. 209, 251-258 (2012).

126. Hedl, M., Li, J., Cho, J.H. \& Abraham, C. Chronic stimulation of Nod2 mediates tolerance to bacterial products. Proc. Natl Acad. Sci. USA 104, 19440-19445 (2007).

127. Platt, A.M., Bain, C.C., Bordon, Y., Sester, D.P. \& Mowat, A.M. An independent subset of TLR expressing CCR2-dependent macrophages promotes colonic inflammation. J. Immunol. 184, 6843-6854 (2010).

128. Roberts, P.J., Riley, G.P., Morgan, K., Miller, R., Hunter, J.O. \& Middleton, S.J. The physiological expression of inducible nitric oxide synthase (iNOS) in the human colon. J. Clin. Pathol. 54, 293297 (2001).

129. Rugtveit, J., Haraldsen, G., Hogasen, A.K., Bakka, A., Brandtzaeg, P. \& Scott, $H$. Respiratory burst of intestinal macrophages in inflammatory bowel disease is mainly caused by CD14 $+\mathrm{L} 1+$ monocyte derived cells. Gut 37, 367-373 (1995).

130. Hirotani, T. et al. The nuclear IkappaB protein IkappaBNS selectively inhibits lipopolysaccharide-induced IL-6 production in macrophages of the colonic lamina propria. J. Immunol. 174, 3650-3657 (2005). 
131. Smith, P.D., Smythies, L.E., Mosteller-Barnum, M., Sibley, D.A. \& Russell, M.W. Merger M et al. Intestinal macrophages lack CD14 and CD89 and consequently are down-regulated for LPS- and IgA-mediated activities. J. Immunol. 167, 2651-2656 (2001).

132. Hoshi, N. et al. MyD88 signalling in colonic mononuclear phagocytes drives colitis in IL-10-deficient mice. Nat. Commun. 3, 1120 (2012).

133. Li, B., Gurung, P., Malireddi, R.K., Vogel, P., Kanneganti, T.D. \& Geiger, T.L. IL-10 engages macrophages to shift Th17 cytokine dependency and pathogenicity during T-cell-mediated colitis. Nat. Commun. 6, 6131 (2015).

134. Ueda, Y. etal. Commensal microbiota induce LPS hyporesponsiveness in colonic macrophages via the production of IL-10. Int. Immunol. 22, 953-962 (2010).

135. Zigmond, E. et al. Macrophage-restricted interleukin-10 receptor deficiency, but not IL-10 deficiency, causes severe spontaneous colitis. Immunity 40, 720-733 (2014).

136. Takeda, K. et al. Enhanced Th1 activity and development of chronic enterocolitis in mice devoid of Stat3 in macrophages and neutrophils. Immunity 10, 39-49 (1999).

137. Glocker, E.O. et al. Inflammatory bowel disease and mutations affecting the interleukin-10 receptor. N. Engl. J. Med. 361, 2033-2045 (2009).

138. Murugan, D. et al. Very early onset inflammatory bowel disease associated with aberrant trafficking of IL-10R1 and cure by T cell replete haploidentical bone marrow transplantation. J. Clin. Immunol. 34, 331339 (2014).

139. Shouval, D.S. et al. Interleukin-10 receptor signaling in innate immune cells regulates mucosal immune tolerance and anti-inflammatory macrophage function. Immunity 40, 706-719 (2014).

140. Kobayashi, T. et al. IL-10 regulates $\| 12 \mathrm{~b}$ expression via histone deacetylation: implications for intestinal macrophage homeostasis. J. Immunol. 189, 1792-1799 (2012).

141. Simon, J.M. et al. Alterations to chromatin in intestinal macrophages link IL-10 deficiency to inappropriate inflammatory responses. Eur. J. Immunol. 46, 1912-1925 (2016).

142. Maheshwari, A. et al. TGF-beta2 suppresses macrophage cytokine production and mucosal inflammatory responses in the developing intestine. Gastroenterology 140, 242-253 (2011).

143. Smythies, L.E. et al. Inflammation anergy in human intestinal macrophages is due to Smad-induced IkappaBalpha expression and NFkappaB inactivation. J. Biol. Chem. 285, 19593-19604 (2010).

144. Schridde, A. et al. Tissue-specific differentiation of colonic macrophages requires TGFbeta receptor-mediated signaling. Mucosal Immunol,; advance online publication, 1 February 2017; doi: 10.1038/ mi.2016.142 (2017).

145. Bosurgi, L. et al. Paradoxical role of the proto-oncogene Axl and Mer receptor tyrosine kinases in colon cancer. Proc. Natl. Acad. Sci. USA 110, 13091-13096 (2013).

146. Bain, C.C. \& Mowat, A.M. CD200 receptor and macrophage function in the intestine. Immunobiology 217, 643-651 (2012).

147. Chen, Z., Yu, K., Zhu, F. \& Gorczynski, R. Over-expression of CD200 protects mice from dextran sodium sulfate induced colitis. PLOS ONE 11, e0146681 (2016).

148. Rossini, V. et al. CX3CR1 $(+)$ cells facilitate the activation of CD4 T cells in the colonic lamina propria during antigen-driven colitis. Mucosal Immunol. 7, 533-548 (2014).

149. Niess, J.H. et al. CX3CR1-mediated dendritic cell access to the intestinal lumen and bacterial clearance. Science 307, 254-258 (2005).

150. Lahiri, A. \& Abraham, C. Activation of pattern recognition receptors upregulates metallothioneins, thereby increasing intracellular accumulation of zinc, autophagy, and bacterial clearance by macrophages. Gastroenterology 147, 835-846 (2014).

151. Battegay, E.J., Raines, E.W., Colbert, T. \& Ross, R. TNF-alpha stimulation of fibroblast proliferation. Dependence on platelet-derived growth factor (PDGF) secretion and alteration of PDGF receptor expression. J. Immunol. 154, 6040-6047 (1995).

152. Pender, S.L., Quinn, J.J., Sanderson, I.R. \& MacDonald, T.T. Butyrate upregulates stromelysin-1 production by intestinal mesenchymal cells. Am. J. Physiol. Gastrointest. Liver Physiol. 279, G918-G924 (2000).
153. Malvin, N.P., Seno, H. \& Stappenbeck, T.S. Colonic epithelial response to injury requires Myd88 signaling in myeloid cells. Mucosal Immunol. 5, 194-206 (2012).

154. Nishikawa, K. et al. Interleukin-17 induces an atypical M2-like macrophage subpopulation that regulates intestinal inflammation. PLOS ONE 9, e108494 (2014).

155. Qualls, J.E., Kaplan, A.M., van Rooijen, N. \& Cohen, D.A. Suppression of experimental colitis by intestinal mononuclear phagocytes. J. Leukoc. Biol. 80, 802-815 (2006).

156. Huynh, D. et al. CSF-1 receptor-dependent colon development, homeostasis and inflammatory stress response. PLoS ONE 8, e56951 (2013).

157. Sauter, K.A. et al. Pleiotropic effects of extended blockade of CSF1R signaling in adult mice. J. Leukoc. Biol. 96, 265-274 (2014).

158. Cosin-Roger, J., Ortiz-Masia, D., Calatayud, S., Hernandez, C., Esplugues, J.V. \& Barrachina, M.D. The activation of Wnt signaling by a STAT6-dependent macrophage phenotype promotes mucosal repair in murine IBD. Mucosal Immunol. 9, 986-998 (2016).

159. D'Angelo, F. et al. Macrophages promote epithelial repair through hepatocyte growth factor secretion. Clin. Exp. Immunol. 174, 60-72 (2013).

160. Ortiz-Masia, D. et al. Hypoxic macrophages impair autophagy in epithelial cells through Wnt1: relevance in IBD. Mucosal Immunol. 7, 929-938 (2014).

161. Schwarz, T. et al. T cell-derived IL-10 determines leishmaniasis disease outcome and is suppressed by a dendritic cell based vaccine. PLOS Pathog. 9, e1003476 (2013).

162. Mortha, A. et al. Microbiota-dependent crosstalk between macrophages and ILC3 promotes intestinal homeostasis. Science 343, 1249288 (2014).

163. Zigmond, E. et al. Ly6C hi monocytes in the inflamed colon give rise to proinflammatory effector cells and migratory antigen-presenting cells. Immunity 37, 1076-1090 (2012).

164. Itano, A.A. et al. Distinct dendritic cell populations sequentially present antigen to CD4 T cells and stimulate different aspects of cell-mediated immunity. Immunity 19, 47-57 (2003).

165. Mazzini, E., Massimiliano, L., Penna, G., Rescigno, M. \& Oral Tolerance, Can Be Established via gap junction transfer of fed antigens from CX3CR1 macrophages to CD103 dendritic cells. Immunity 40, 248-261 (2014).

166. Cohen, S.B., Maurer, K.J., Egan, C.E., Oghumu, S., Satoskar, A.R. \& Denkers, E.Y. CXCR3-dependent CD4(+) T cells are required to activate inflammatory monocytes for defense against intestinal infection. PLOS Pathog. 9, e1003706 (2013).

167. Dunay, I.R. \& Sibley, L.D. Monocytes mediate mucosal immunity to Toxoplasma gondii. Curr. Opin. Immunol. 22, 461-466 (2010).

168. Kim, Y.G. et al. The Nod2 sensor promotes intestinal pathogen eradication via the chemokine CCL2-dependent recruitment of inflammatory monocytes. Immunity 34, 769-780 (2011).

169. Waddell, A. et al. Colonic eosinophilic inflammation in experimental colitis is mediated by Ly6C(high) CCR2 $(+)$ inflammatory monocyte/macrophage-derived CCL11. J. Immunol. 186, 5993-6003 (2011).

170. Schulthess, J. et al. Interleukin-15-dependent NKp46 + innate lymphoid cells control intestinal inflammation by recruiting inflammatory monocytes. Immunity 37, 108-121 (2012).

171. Kim, K.W. et al. In vivo structure/function and expression analysis of the CX3C chemokine fractalkine. Blood 118, e156-e167 (2011).

172. Niess, J.H. \& Adler, G. Enteric flora expands gut lamina propria CX3CR1 + dendritic cells supporting inflammatory immune responses under normal and inflammatory conditions. J. Immunol. 184, 2026-2037 (2010).

173. Askenase, M.H. et al. Bone-marrow-resident NK cells prime monocytes for regulatory function during infection. Immunity 42, 1130-1142 (2015).

174. Arnold, I.C., Mathisen, S., Schulthess, J., Danne, C., Hegazy, A.N. \& Powrie, F. CD11C(+) monocyte/macrophages promote chronic Helicobacter hepaticus-induced intestinal inflammation through the production of IL-23. Mucosal Immunol. 9, 352-363 (2016).

175. Grainger, J.R. et al. Inflammatory monocytes regulate pathologic responses to commensals during acute gastrointestinal infection. Nat. Med. 19, 713-721 (2013). 
176. Grimm, M.C., Pavli, P., Van de Pol, E. \& Doe, W.F. Evidence for a CD14 + population of monocytes in inflammatory bowel disease mucosaimplications for pathogenesis. Clin. Exp. Immunol. 100, 291-297 (1995).

177. Schreiber, H.A. et al. Intestinal monocytes and macrophages are required for T cell polarization in response to Citrobacter rodentium. J. Exp. Med. 210, 2025-2039 (2013).

178. Waddell, A. et al. Intestinal CCL11 and eosinophilic inflammation is regulated by myeloid cell-specific RelA/p65 in mice. J. Immunol. 190, 4773-4785 (2013).

179. deSchoolmeester, M.L., Little, M.C., Rollins, B.J. \& Else, K.J. Absence of CC chemokine ligand 2 results in an altered Th1/Th2 cytokine balance and failure to expel Trichuris muris infection. J. Immunol. 170, 4693-4700 (2003).

180. Filbey, K.J. et al. Innate and adaptive type 2 immune cell responses in genetically controlled resistance to intestinal helminth infection. Immunol. Cell Biol. 92, 436-448 (2014).

181. Kreider, T., Anthony, R.M., Urban, J.F. Jr. \& Gause, W.C. Alternatively activated macrophages in helminth infections. Curr. Opin. Immunol. 19, 448-453 (2007).

182. Little, M.C., Hurst, R.J. \& Else, K.J. Dynamic changes in macrophage activation and proliferation during the development and resolution of intestinal inflammation. J. Immunol. 193, 4684-4695 (2014).

183. Schmidt, S. et al. Nippostrongylus-induced intestinal hypercontractility requires IL-4 receptor alpha-responsiveness by Tcells in mice. PLOSONE 7, e52211 (2012).

184. Nelson, S.M., Shay, A.E., James, J.L., Carlson, B.A., Urban, J.F. Jr. \& Prabhu, K.S. Selenoprotein expression in macrophages is critical for optimal clearance of parasitic Helminth Nippostrongylus brasiliensis. J. Biol. Chem. 291, 2787-2798 (2016).

185. Ruckerl, D. \& Allen, J.E. Macrophage proliferation, provenance, and plasticity in macroparasite infection. Immunol. Rev. 262, 113-133 (2014).

186. Anthony, R.M. et al. Memory $\mathrm{T}(\mathrm{H}) 2$ cells induce alternatively activated macrophages to mediate protection against nematode parasites. Nat. Med. 12, 955-960 (2006)

187. Notari, L. et al. Role of macrophages in the altered epithelial function during a type 2 immune response induced by enteric nematode infection. PLOS ONE 9, e84763 (2014).

188. Zhao, A. et al. Th2 cytokine-induced alterations in intestinal smooth muscle function depend on alternatively activated macrophages. Gastroenterology 135, 217-225 e211 (2008).

189. Jenkins, S.J. et al. Local macrophage proliferation, rather than recruitment from the blood, is a signature of TH2 inflammation. Science $\mathbf{3 3 2}$, 1284-1288 (2011).

190. Jenkins, S.J. et al. IL-4 directly signals tissue-resident macrophages to proliferate beyond homeostatic levels controlled by CSF-1. J. Exp. Med. 210, 2477-2491 (2013).

191. Rani, R., Smulian, A.G., Greaves, D.R., Hogan, S.P. \& Herbert, D.R. TGFbeta limits IL-33 production and promotes the resolution of colitis through regulation of macrophage function. Eur. J. Immunol. 41, 2000-2009 (2011).

192. Pull, S.L., Doherty, J.M., Mills, J.C., Gordon, J.I. \& Stappenbeck, T.S. Activated macrophages are an adaptive element of the colonic epithelial progenitor niche necessary for regenerative responses to injury. Proc. Natl Acad. Sci. USA 102, 99-104 (2005).

193. Esser-von Bieren, J. et al. Immune antibodies and helminth products drive CXCR2-dependent macrophage-myofibroblast crosstalk to promote intestinal repair. PLoS Pathog. 11, e1004778 (2015).

194. Mizuno, S. et al. Cross-talk between RORgammat + innate lymphoid cells and intestinal macrophages induces mucosal IL-22 production in Crohn's disease. Inflamm. Bowel Dis. 20, 1426-1434 (2014).

195. Duffield, J.S., Lupher, M., Thannickal, V.J. \& Wynn, T.A. Host responses in tissue repair and fibrosis. Annu. Rev. Pathol. 8, 241-276 (2013).

196. Herbert, D.R. et al. Arginase I suppresses IL-12/L-23p40-driven intestinal inflammation during acute schistosomiasis. J. Immunol. 184, 6438-6446 (2010).

197. Bersudsky, M. et al. Non-redundant properties of IL-1alpha and IL-1beta during acute colon inflammation in mice. Gut 63, 598-609 (2014).

198. Scheibe, K. et al. IL-36R signalling activates intestinal epithelial cells and fibroblasts and promotes mucosal healing in vivo. Gut pii: gutjnl-2015310374 (2016).
199. Epelman, S. et al. Embryonic and adult-derived resident cardiac macrophages are maintained through distinct mechanisms at steady state and during inflammation. Immunity 40, 91-104 (2014).

200. Scott, C.L. et al. Bone marrow-derived monocytes give rise to selfrenewing and fully differentiated Kupffer cells. Nat. Commun. 7, 10321 (2016).

201. Dabritz, J. etal. Reprogramming of monocytes by GM-CSF contributes to regulatory immune functions during intestinal inflammation. J. Immunol. 194, 2424-2438 (2015).

202. D'Alessio, S. et al. VEGF-C-dependent stimulation of lymphatic function ameliorates experimental inflammatory bowel disease. J. Clin. Invest. 124, 3863-3878 (2014).

203. Kamada, N. et al. Unique CD14 intestinal macrophages contribute to the pathogenesis of Crohn disease via IL-23/IFN-gamma axis. J. Clin. Invest. 118, 2269-2280 (2008).

204. Lampinen, M., Waddell, A., Ahrens, R., Carlson, M. \& Hogan, S.P. CD14 + CD33 + myeloid cell-CCL11-eosinophil signature in ulcerative colitis. J. Leukoc. Biol. 94, 1061-1070 (2013).

205. Mann, E.R. et al. Intestinal dendritic cells: their role in intestinal inflammation, manipulation by the gut microbiota and differences between mice and men. Immunol. Lett. 150, 30-40 (2013).

206. Rogler, G. et al. Nuclear factor kappaB is activated in macrophages and epithelial cells of inflamed intestinal mucosa. Gastroenterology 115, 357369 (1998).

207. Hedl, M. \& Abraham, C. Negative regulation of human mononuclear phagocyte function. Mucosal Immunol. 6, 205-223 (2013).

208. Kuhl, A.A., Erben, U., Kredel, L.I. \& Siegmund, B. Diversity of intestinal macrophages in inflammatory bowel diseases. Front. Immunol. 6, 613 (2015).

209. Rugtveit, J., Brandtzaeg, P., Halstensen, T.S., Fausa, O. \& Scott, H. Increased macrophage subset in inflammatory bowel disease: apparent recruitment from peripheral blood monocytes. Gut 35, 669674 (1994).

210. Thiesen, S. et al. CD14(hi)HLA-DR(dim) macrophages, with a resemblance to classical blood monocytes, dominate inflamed mucosa in Crohn's disease. J. Leukoc. Biol. 95, 531-541 (2014).

211. Ogino, T. et al. Increased Th17-inducing activity of CD14(+) CD163(low) myeloid cells in intestinal lamina propria of patients with Crohn's disease. Gastroenterology 145, 1380-1391 e1381 (2013).

212. Rugtveit, J., Nilsen, E.M., Bakka, A., Carlsen, H., Brandtzaeg, P. \& Scott, $H$. Cytokine profiles differ in newly recruited and resident subsets of mucosal macrophages from inflammatory bowel disease. Gastroenterology 112, 1493-1505 (1997).

213. Tamoutounour, S. et al. Origins and functional specialization of macrophages and of conventional and monocyte-derived dendritic cells in mouse skin. Immunity 39, 925-938 (2013).

214. Chen, S., Luo, D., Streit, W.J. \& Harrison, J.K. TGF-beta1 upregulates CX3CR1 expression and inhibits fractalkine-stimulated signaling in rat microglia. J. Neuroimmunol. 133, 46-55 (2002).

215. Papadakis, K.A. et al. Kruppel-like factor KLF10 deficiency predisposes to colitis through colonic macrophage dysregulation. Am. J. Physiol. Gastrointest. Liver Physiol. 309, G900-G909 (2015).

216. Okabe, Y. \& Medzhitov, R. Tissue biology perspective on macrophages. Nat. Immunol. 17, 9-17 (2016).

217. Paul, F. et al. Transcriptional heterogeneity and lineage commitment in myeloid progenitors. Cell 163, 1663-1677 (2015).

218. Chopin, M. et al. Langerhans cells are generated by two distinct PU.1dependent transcriptional networks. J. Exp. Med. 210, 2967-2980 (2013).

219. Greter, M. et al. GM-CSF controls nonlymphoid tissue dendritic cell homeostasis but is dispensable for the differentiation of inflammatory dendritic cells. Immunity 36, 1031-1046 (2012).

220. Ochi, T. et al. Diet-dependent, microbiota-independent regulation of IL10 -producing lamina propria macrophages in the small intestine. Sci. Rep. 6, 27634 (2016).

221. Chang, P.V., Hao, L., Offermanns, S. \& Medzhitov, R. The microbial metabolite butyrate regulates intestinal macrophage function via histone deacetylase inhibition. Proc. Natl Acad. Sci. USA 111, 22472252 (2014)

222. Franchi, L. et al. NLRC4-driven production of IL-1beta discriminates between pathogenic and commensal bacteria and promotes host intestinal defense. Nat. Immunol. 13, 449-456 (2012). 
223. Hontecillas, R. et al. Immunoregulatory mechanisms of macrophage PPAR-gamma in mice with experimental inflammatory bowel disease. Mucosal Immunol. 4, 304-313 (2011).

224. Manoharan, I. et al. Homeostatic PPARalpha signaling limits inflammatory responses to commensal microbiota in the intestine. J. Immunol. 196, 4739-4749 (2016).
225. Mizutani, N. et al. Dose-dependent differential regulation of cytokine secretion from macrophages by fractalkine. J. Immunol. 179, 7478-7487 (2007).

226. Ngoh, E.N. et al. Activity of SHIP, which prevents expression of interleukin 1 beta, is reduced in patients with Crohn's disease. Gastroenterology 150 , 465-476 (2016). 